\title{
Cellular Mechanisms of Pattern Formation in the Developing Limb
}

\author{
P. K. MAINI* AND M. Solursh $\dagger$ \\ * Department of Mathematics, University of Utah, Salt Lake City, Utah 84112 \\ † Department of Biology, University of Iowa, Iowa City, Iowa 52242
}

\section{Introduction}

Development of spatial pattern and form is an important, yet poorly understood phenomenon in embryology. Although genes ultimately control pattern formation, the study of the genetic aspects alone will not elucidate the mechanisms by which the developmental pathways of individual cells in a multicellular system are determined in a spatially coordinated manner. Morphogenesis of the vertebrate limb is particularly amenable to biological analysis and has been widely studied both experimentally and theoretically. It is believed that the process of limb development in mammals is similar to that in the chick, and thus, understanding the process in the chick would greatly enhance the understanding of development in other vertebrate systems. Moreover, the insights gained in understanding limb development may help in understanding the mechanisms at work in other types of pattern formation in developmental biology.

Limb development consists of a series of sequential processes. Initially, the limb site is determined, then polarity is established, and outgrowth ensues. As the limb elongates, the skeletal pattern appears in a proximodistal sequence. The stabilization of each element follows after a period in which cell determination is labile and may be influenced by external factors. Overt cell differentiation can then be recognized by the synthesis of cell type-specific molecules. Thus, in order to understand the underlying mechanisms involved in limb development, one must investigate how the sequential events of a particular process are initiated and stabilized, and how this, in turn, affects the initiation and time evolution of subsequent processes.

In this chapter we review the experimental and theoretical work on limb development in the chick wing, concentrating mainly on the musculature and skeletal pattern. Section II gives an overview of the sequence of events during early limb development and a brief description of limb outgrowth. In Section III we discuss pattern formation along the different axes of the limb and the importance of specialized regions in the wing. In 


\section{Establishment of Polarity}

Limb polarity is determined long before outgrowth is visible. Chaube (1959) transplanted the presumptive wing bud region in different orientations onto host embryos and deduced that the AP axis within the wing bud is determined before stage 8 and that the dorsal-ventral (DV) axis is determined between stage $11^{-}$and stage 11 . As with the initiation of the limb site, it is not known what determines the polarity of the limb. Homeobox gene expression may be an important factor (see Section III, D), but this simply begs the question, that is, what causes the polarity in homeobox gene expression?

\section{Limb Outgrowth}

Wing outgrowth is apparent by stage 17 when a limb bud is formed. Prior to this, the presumptive wing region is flat. At stage 7 it is roughly circular, measuring $0.22 \mathrm{~mm}$ along the AP axis and $0.20 \mathrm{~mm}$ along the DV axis. Between stages 7 and 14, AP expansion is considerably greater than DV expansion. Anterior-posterior expansion is uniform up to stage 16 (Chaube, 1959). At this stage, the wing bud elongates rapidly. It is unknown how this elongation occurs. It may be due to the greater rate of mitosis of mesenchymal cells in the presumptive limb region compared to the cells of the surrounding flank tissue, where the mitotic rate falls (Searls and Janners, 1971). Alternatively, outgrowth may be due to the difference in adhesive properties between presumptive limb region cells and those from the surrounding flank region (Heintzelman et al., 1978). Recently, Solursh et al. (1990) found that syndecan, a membrane proteoglycan that links the cell cytoskeleton to interstitial extracellular matrix components, appears localized in the limb bud during the initial stages of outgrowth. Thus the cells of the presumptive limb site may be more cohesive than those of the surrounding flank region, causing them to stick together and form a cohesive outgrowth.

Recent observations (Geduspan and Solursh, 1990) shown that the mesonephros can induce outgrowth and chondrogenesis of a limb bud in culture. In vivo, limb outgrowth does not occur if the mesonephros is removed.

The outgrowing developing limb bud is encased in an ectodermal covering. The interior of the bud is composed of mesenchymal cells which eventually differentiate into cartilage, bone, connective tissue, and blood vessels; and premuscle cells which form the muscle masses. As outgrowth proceeds, skeletal elements and muscle masses are observed to occur in a sequential fashion. 
more, in the above experiment the ZPA may not have been completely removed (Summerbell, 1979).

Multiple ZPA grafts lead to multiple duplications (Wolpert and Hornbruch, 1981; Iten et al., 1981; Summerbell, 1981). The duplicating ability of the ZPA can be attenuated either by irradiating the ZPA with $\gamma$ radiation (Smith et al., 1978) or by decreasing the number of cells in the graft (Tickle, 1981a); both these procedures lead to incomplete duplication. It appears that the signal is not transmitted across the entire AP axis of the limb, and that cooperation between the polarizing cells and an intact apical ectodermal ridge (AER) is important for positional signaling (Tickle et al., 1975). Furthermore, functional gap junctions are required for polarizing region cells to communicate with anterior mesenchyme, since blocking antibodies to rat liver gap junctional proteins block polarizing zone induced limb duplications (Allen et al., 1990). It appears that only cells in the progress zone are capable of responding to the duplicating property of the ZPA (Summerbell, 1974a). These may be the same cells that express Hox7.1 (Hill et al., 1989; Robert et al., 1989). The continued presence of the grafted ZPA is not necessary for duplication, suggesting that cells are capable of remembering exposure to ZPA (Smith, 1979). However, in this case, the cells in the progress zone may, in fact, be responding to the progeny of ZPA cells.

Wilson and Hinchliffe (1987) removed the posterior half of stage 20-23 wing buds and grafted stage 20-23 ZPA to the posterior surface of the remaining anterior half. Grafts made proximally to the cut surface did not result in a significant improvement in development nor did they prevent extensive cell death. However, if the graft was made distally in contact with the AER, cell death was inhibited and the anterior mesenchyme changed its normal fate and formed a full skeleton in almost half the cases.

The ZPA is not unique in its ability to stimulate the formation of supernumerary digits. Posterior mesenchyme from amniotes can produce similar effects (Fallon and Crosby, 1977). Anterior non-ZPA limb tissue and even nonlimb tissue implants can induce supernumerary digits (Iten and Murphy, 1980; Saunders and Gasseling, 1983; Hornbruch and Wolpert, 1986; Stocker and Carlson, 1990). Duplication can also be achieved by treatment with retinoic acid (RA).

\section{Retinoic Acid}

Several experiments have been performed to try to mimic the results of ZPA grafting experiments in the attempt to understand the underlying mechanisms involved. Tickle et al. (1982) found that paper impregnated with RA implanted at the anterior region of the wing bud gave supernumerary digits. This suggested that RA may be the morphogen to which cells 


\section{B. Dorsal-Ventral Development}

The DV height increases from $0.3 \mathrm{~mm}$ at stage 18 to $0.63 \mathrm{~mm}$ at stage 25 , most of the increase occurring in the muscle masses outside the central chondrogenic core (Stark and Searls, 1973). At stage 17 the bud is roughly elliptical in cross section and flattened dorsoventrally. As the digits begin to form, the dorsoventral flattening becomes more pronounced distally, forming a paddle-shaped limb bud.

\section{Control of Pattern}

Stark and Searls (1974) found that the dorsal and ventral ectoderm appeared to help stabilize the cartilage pattern in the wing and to influence the development of the humerus. Recently, it has been shown that between stages 14 and 16 the wing mesoderm transmits information to the ectoderm which enables the ectoderm to control the DV polarity of cartilage, musculature, and feather pattern in the limb (Geduspan and MacCabe, 1986, 1987). Stage 14 mesoderm can reprogram DV information in the ectoderm up to stage 18 (Geduspan and MacCabe, 1989).

\section{Proximal-Distal Development}

Initially the dorsal region of the limb bud divides more rapidly than the ventral region, so that the dorsal half produces most of the limb primordium (Geduspan and Solursh, 1990). By stage 21 the limb bud becomes asymmetric - the proximal-distal (PD) axis is directed ventrally, the bud apex is posterior to the midline bisecting the base of the bud, and the posterior half elongates rapidly (Saunders, 1948). The PD length (somite to tip of wing) increases linearly with time from stage 18 to 25 (Lewis, 1975). By stage 25, the PD length has increased from $0.23 \mathrm{~mm}$ to $1.74 \mathrm{~mm}$ while the AP length has changed only slightly. The formation of the elbow region begins to exert its influence by stage 26 , causing the wing bud to bend. Control of PD elongation appears to reside in a specialized ridge region of the ectoderm at the apex of the limb bud, the AER. The requirement for the AER for continued elongation is nicely illustrated by the wingless mutant which initially forms a wing bud that subsequently fails to elongate due to a defect in the ectoderm (Carrington and Fallon, 1984).

\section{Sequence of Events}

The skeletal elements are observed to form in a PD and posterioranterior sequence. The first detectable sign of differentiation in the mesenchyme is the uptake of radioactive labeled sulphate into mucopolysaccha- 
have the same regulative ability as the humerus, that is, regulative ability does not appear to change along the PD axis. The abnormal wings resulting from excision of prospective long bone regions also had digit deficiencies. The normal wings that resulted from these experiments were often smaller than the contralateral control, although all the skeletal elements were normally proportioned. The authors suggest that these results can be explained by assuming that stabilization (lack of regulation) is due to advanced state of differentiation and to decreased rate of cell division after stage 22. The delay in development that occurs in wings that have had $50 \%$ of their prospective chondrogenic regions removed at stage 19 or 20 is 10-13 hours, the same as the cell generation time. Rotation of the elbow region showed mosiac properties by stage 23 . Prior to this stage, the development of the humerus was disrupted, but the radius and ulna formed normally. Rotation during stage 24 resulted in a reversed " $Y$ " pattern. These results are consistent with those of Searls and Janners (1969) who found that hosts implanted with small blocks of mesoderm were able to regulate up to stage 24 .

Summerbell (1977) removed whole slices of tissue from the prospective elbow region of stage 19-25 wing buds along the PD axis. He found that prior to stage 22 the limb bud showed some regulation, but there was no regulation in stage 22 or older wing buds. His statistical analysis suggests that a significant proportion of the wing may remain in the flank up to stage 24-he cut out a slice bordering the proximal base of the bud and found that the proportion of presumptive skeleton lying in the flank was significantly greater than zero in experiments done on limbs from stages 19 to 24 but not significant for stage 25 .

Kieny (1977) analyzed PD regulation during stages 18-22 by grafting an entire limb onto a presumptive wrist or ankle stump, creating excess limb tissue; and grafting presumptive autopod onto a presumptive stylopod stump, creating a limb with deficient tissue. In the former experiment, about $19 \%$ of the limbs regulated to give a normal limb. In these cases, the stylopod and zeugopod of the stump and the stylopod of the graft gave rise to a single basal element. A surplus of one or two segments occurred in 43 and $38 \%$ of cases, respectively. The latter experiment leads to regulation in most cases. Heterotopic leg/wing, chick/quail, and carbon marking experiments show that both stump and graft tissues contribute to the regulated zeugopod. If these experiments are performed once overt differentiation is near (stage 24), regulation is not possible.

These results show that the limb is capable of PD regulation at early stages and that the proximal part in the limb regulates to a greater extent than does the distal part.

In contrast to the results of the above experiments, Wolpert et al. (1975) 
the AER depended on the stage at which the AER was removed. From this he concluded that cartilage elements are laid down sequentially along the PD axis. Summerbell (1974b) presented a quantitative analysis of the effects of AER removal at different stages on the PD sequence of skeletal development. He found that removal of the AER at stage 18 gave rise to a wing which was truncated at the midhumerus level. The level of truncation progressed down the PD axis as the operation was performed at later stages; thus stage 19 gave the humerus, stages 19-20 the ulna and radius, stages 21-24 the wrist, stages 25-26 the metacarpal of digit III, stage 27 the proximal phalanx, and stage 28 the distal element of digit III. In the majority of cases, the terminal bone was significantly shorter than in the contralateral control element, suggesting that the pattern is laid down continuously. Qualitatively similar behavior occurs in the developing leg bud (Rowe and Fallon, 1982).

Summerbell (1976) observed that the length of the progress zone does not change gradually, rather it does so in jumps corresponding to the appearance of elements at each PD level, suggesting that the patterning process is discrete. This contradicts his earlier work (Summerbell, 1974b) but does support the idea that each element initially consists of an aggregation of cells which differentiates when a certain size of condensation is reached.

Zwilling found that thin strips of stage 18-20 limb apical mesoderm with the AER attached can give rise to whole limbs when grafted to the flank (Zwilling, 1955, 1956a). Furthermore, the proximal mesoblast could also form an entire limb if encased in a limb ectodermal jacket. Ectoderm-free or nonlimb ectoderm-covered mesoblast did not form a limb. He also showed that grafting an AER to the dorsal side of an intact limb resulted in two complete limbs. If the grafted AER is placed in the body cavity at the base of the limb, a supernumerary limb grew into the somatopleure. Zwilling and Hansborough (1956) observed that the polydactylous mutant appears to have an AER that is thickened both posteriorly and anteriorly. They interchanged stage 18-20 ectoderm and mesoderm from polydactylous limbs with those from normal limbs and found that mutant ectoderm and normal mesoderm gave rise to normal pattern, whereas normal ectoderm with mutant mesoderm gave rise to a polydactylous wing, together with a more extensive AER. These results suggest that the pattern resides in the mesoderm and that the latter influences ectoderm development.

In the wingless mutant, distal development of the wing ceases at the same time as the AER disappears. Combining mutant ectoderm with normal mesoderm did not improve limb development (Zwilling, 1956b) suggesting that the mutation is in the ectoderm. Furthermore, mutant mesoderm overlain with normal ectoderm underwent more distal develop- 
characterized in limb development. This is particularly true of genes containing the homeobox, a 180-base pair motif encoding a DNA-binding domain of a multigene family of proteins (Gehring, 1987). In the limb bud, there is presently only provocative descriptive information about the spatial and temporal patterns of expression of these genes with little information about function. Some of these regulatory genes may integrate responses to organizing influences such as the AER or retinoids. For example, the XIH box I is expressed in a concentration gradient that runs opposite to that of RA and its expression might be inhibited by RA (Oliver et al., 1988, 1989). Hox 5.2 is expressed complimentary to XIH box I (Oliver et al., 1989). Further, members of the Hox 5 complex are expressed in sequential but overlapping domains during limb development in a manner which suggests that they might be responsive to retinoids derived from the polarizing zone (Dolle et al., 1989a). Subsequently Hox 5.2 and 5.3 are expressed in cartilage elements (Dollé and Duboule, 1989). Another homeobox-containing gene, Hox 7.1, is expressed in the distal mesenchyme and adjacent AER (Robert et al., 1989; Hill et al., 1989) and the polarizing zone (Hill et al., 1989). While these distributions are provocative, the actual functions of these gene products in pattern formation awaits careful analysis.

\section{Differentiation}

The molecular mechanisms of cell differentiation in the limb are not fully understood (for review see Caplan, 1977). The wing musculature is normally of somitic origin, whereas connective tissues, such as cartilage and bone, are derived from the somatopleure (Chevallier et al., 1977; Christ et al., 1977). Cells that eventually differentiate into cartilage are known as precartilage cells, those that differentiate into muscle are called premyogenic cells. In vitro studies suggest that chondrogenesis and myogenesis occur independently of each other, and that their differentiation is regulated by different mechanisms. For example, Swalla and Solursh (1986) compared myogenic expression in micromass cultures that exhibit very different chondrogenic capacities and found no significant difference in myoblast concentration. On the other hand, Sasse et al. (1984) separated premyogenic cells from stage 20,21 , and 22 limb buds. They found that these cells differentiated into muscle and that the remaining cell culture largely differentiated into cartilage. They were unable to change the fate of either cell type by culturing in medium known to promote the other type of differentiation. However, they found that removal of myogenic cells in culture resulted in a dramatic increase of chondrogenesis from the remain- 
central core of the proximal half of the limb begin to increase their rate of glycosaminoglycan synthesis. These changes occur between stages 22 and 24 and are experimentally reversible. Searls and Janners (1969) found that blocks of cartilage forming mesenchyme generally conformed with the host limb pattern if both the donor and the host were stage 24 or younger. A block of cartilage-forming mesenchyme generally did not conform with the host pattern if the donor was stage 25 or older, regardless of the stage of the host. Older hosts (stages 25-27) had reduced ability to direct differentiation of stage 24 donors. They concluded that cartilage-forming cells become stabilized between stages 24 and 25 and that this is a gradual process.

Contrary to these results, Wachtler et al. (1981) found that in chickquail recombinants, mesenchyme that would normally form connective tissue could form cartilage if placed in the prechondrogenic core, while cells from the latter could differentiate into connective tissue if placed in the appropriate regions, up to stage 20 . From stage 20, mesenchyme in the cartilage regions is determined to give rise only to cartilage, but tissue from noncartilage-forming regions can form cartilage up to stage 26 , at least. This suggests that stabilization of differentiation begins at an earlier stage than that implied by the observations mentioned above. The different results could be due to the greater sensitivity of the quail nucleolar marking systems as well as to contributions by cell heterogeneity.

\section{B. Factors Affecting Chondrogenesis}

A variety of factors can affect phenotypic expression in cell cultures but it is not known to what extent these are involved in situ.

\section{Cell Aggregation}

In vitro studies suggest that there are two main stages in the onset of cartilage formation (Thorogood and Hinchliffe, 1975; Ahrens et al., 1977; Hinchliffe and Johnson, 1980); first, mesenchymal cells form precartilage aggregates, then the cells in each aggregate differentiate into chondrocytes. It is known that the apparent cell density increases prior to condensation (Fell and Canti, 1934) but it is not clear whether this is due to active cell aggregation or to a change in the ECM that brings the cells together. Indeed, it is possible that this phenomenon is merely a fixation artifact reflecting localized differences in the condensation of the ECM (Singley and Solursh, 1981). Recently, Aulthouse and Solursh (1987) used peanut agglutinin, which is a marker for precartilage cellular aggregates both in vivo and in vitro, to show that in both these cases cell aggregation appears to precede differentiation. Aggregate formation is associated with the accumulation of new ECM components (Solursh, 1990; Shinomura and 
fibronectin (Swalla and Solursh, 1984). In both these cases, cytochalasin D reverses the inhibitory effect. These treatments of single cells might imitate changes that occur in multicellular aggregates.

It is possible, however, for cells in an elongated configuration to differentiate into cartilage. Inoue et al. (1989), for example, found that chick and rabbit chondrocytes treated with fibroblast growth factor and transforming growth factor- $\beta$ (TGF- $\beta$ ) produced a large amount of type II collagen even though the cells themselves were elongated. Thus, the gross appearance of the cell is not necessarily crucial for the synthesis of type II collagen. Instead, the fine intracellular architecture of the cytoskeleton may be the determining factor. Such a hypothesis agrees with the results of Zanetti and Solursh (1984). They found that agents that disrupt the microtubules have no apparent effect on the shape or chondrogenic differentiation of limb bud mesenchymal cells. Thus it appears that the actin cytoskeleton is involved in controlling the cell shape and that behavior that seems to be attributable to cell shape may, in fact, be due to the structure of the actin cytoskeleton.

\section{Ectodermal Effects}

Both the AER and non-AER ectoderm are very important for cell differentiation both in vivo and in vitro (see Solursh, 1984b, for a review on the ectoderm). In this section we shall review both the inhibitory and stimulatory effects of the ectoderm on chondrogenesis.

That the ectoderm inhibits chondrogenesis is apparent from the observation that normally, nonchondrogenic limb mesenchyme forms extensive cartilage in culture (see, e.g., Ahrens et al., 1979; Cottrill et al., 1987a). The inhibitory effect of the ectoderm may be due to effects on cell shape as cells in the periphery are flattened compared to cells in the prechondrogenic core (Solursh et al., 1981). Ectoderm enhances cell flattening in vitro (Zanetti and Solursh, 1986; Zanetti et al., 1990).

Solursh et al. (1984) found that chondrogenesis of mesenchymal cells cultured in collagen gels could be inhibited by preconditioning the gel with ectoderm or by placing ectoderm over the cells, a result confirmed by observations with micromass culture (Gregg et al., 1989). Cell contact is not necessary-inhibition occurs even when a filter separates the ectoderm from the gel. These results suggest that the ectoderm influences cartilage differentiation by modifying the collagenous extracellular matrix through some diffusible substance, and that such a modification is stable. The ectoderm, however, does not behave in a purely inhibitory manner in vitro. The form of the ectodermal-mesodermal interaction is stage dependent. Solursh and Reiter (1988) compared the effects of stage 15/16 and stage 23/24 wing bud ectoderm on wing bud mesenchyme cultured in 


\section{Myogenesis}

Premyogenic cells migrate from the somites into the wing bud between stages 14 and 18 (Christ et al., 1977; Chevallier et al., 1977). Initially, myoblasts appear to be uniformly spread throughout the wing bud. By stage 21, they begin to localize in the dorsal and ventral peripheral regions (Schramm and Solursh, 1990). By stage 23 the distinction between myogenic and chondrogenic regions is more pronounced, although some myogenic cells are still observed in the core. It is at this stage that the accumulation of laminin is detected in the forming premuscle masses (Solursh and Jensen, 1988) and that muscle-specific gene transcription is detected in situ (Swiderski and Solursh, 1990). In the intact limb, the leading myoblasts remain about $300 \mu \mathrm{m}$ from the distal tip and migrate in a PD direction (Wachtler et al., 1981). By stage 25, myoblasts account for $<0.05 \%$ of the total distal cells (Archer et al., 1989). By stage 25, the muscle masses can be detected by the presence of muscle-specific proteins (Sweeny et al., 1989).

\section{Factors Affecting Myogenesis}

It appears that the patterning of the skeletal muscles is dependent on the migration of the myogenic cells. Chevailler and Keiny (1982) implanted premuscle quail cells into the presumptive wing regions of a chick host in which the somitic mesoderm that would give rise to the musculature had been destroyed. They found that implanted myogenic cells which had already gone through the migratory phase in the donor were able to migrate distally and to respond to the patterning cues of the host presumptive muscular connective tissue when placed in contact with it. However, implants of myogenic cells which had not undergone migration to the limb site in the donor did not differentiate into organized skeletal muscle in the host.

\section{Role of Vasculature}

It is not known how premuscle cell migration is initiated nor how it is directed. It has been suggested that the vascular network may provide an initial cue for migration of myoblasts (Solursh et al., 1987). Presumptive myogenic cells just migrating from the somite wall first contact vascular endothelial cells. Additional support for this hypothesis comes from the observations that myoblasts are capable of responding chemotactically to platelet-derived growth factor (PDGF) (Venkatasubramanian and Solursh, 1984) and that endothelial cells can produce a PDGF-like protein (DiCorleto and Bowen-Pope, 1983).

Caplan and Koutroupas (1973) showed that stage 24 limb mesodermal 
Jensen, 1988). Myoblasts are known to synthesize laminin in vitro and laminin enhances myoblast adhesion and promotes their proliferation and migration (Kuhl et al., 1982; Olwin and Hall, 1985; Von der Mark and Kuhl, 1985; Kuhl et al., 1986; Ocalan et al., 1988; Von der Mark and Ocalan, 1989). This suggests that laminin may play an important role in in vivo myogenesis.

\section{F. Role of Growth Factors in Limb Patterning}

It has become clear that growth factors have dramatic actions on cell growth and differentiation. Most of the available information is concerned with actions of cell cultures. It is known, however, that fibroblastic growth factor (FGF) is present in the limb bud (Seed et al., 1988; Munaim et al., 1988). In high concentrations, FGF has different effects on the growth of limb bud mesenchyme depending on the origin of the mesenchyme along the AP limb axis (Aono and Ide, 1988). Transcripts for several members of the TGF- $\beta$ family have been localized in the limb bud and have complex patterns of expression (Lyons et al., 1989, 1990). In the case of bone morphogenetic protein-2A (BMP-2A) it appears first in the ventral limb ectoderm and later in the AER. The effect of TGF- $\beta$ on chondrogenesis varies with the stage of differentiation of the cells (Carrington and Reddi, 1990; Kulyk et al., 1989a), the dose (Joyce et al., 1990), and the presence of other growth factors (see, e.g., Horton et al., 1989). Other growth factors are no doubt present as well. The roles of these biologically potent agents and their receptors are still poorly understood but it is already clear that they play a central role in pattern formation.

\section{Theoretical Models for Limb Development}

To date, modeling has largely concentrated on the process of chondrogenesis and, in particular, on the generation of spatially heterogeneous patterns of differentiated cells from an initially spatially homogeneous population of mesenchymal cells. In this section we shall critique some of the models proposed for patterning in the limb. We shall outline the hypotheses behind each model, describe its mathematical formulation, and compare the predictions of each model with experimental observations. In Section V, A we describe the gradient model and in Section V, B, the progress zone model. Reaction diffusion models and mechanochemical models are discussed in Sections V, C and D, respectively. In Sections $\mathrm{V}, \mathrm{E}$ and $\mathrm{F}$, respectively, we briefly mention the differential adhesion model and the polar coordinate model. In Section V, G we compare all the aforementioned models. 
Grafting a donor ZPA to the anterior of the host leads to a morphogen source on the right hand boundary also, and the steady state morphogen concentration is given by

$$
S(x)=\frac{S_{0}\left\{\sinh \left[\gamma\left(d_{1}-x\right)\right]+\sinh (\gamma x)\right\}}{\sinh \left(\gamma d_{1}\right)}
$$

Zone of polarizing activity transplants result in the widening of the limb bud (Smith and Wolpert, 1981) so the new AP width, $d_{1}$, is greater than $d$. Equation (4) describes a symmetric concentration about the midpoint of the AP axis and suggests that an AP symmetric skeletal pattern with duplication should develop.

\section{Critique of the Model}

The preaxial portion of the limb will maintain the AER in the presence of polarizing activity. Using this as an in vitro assay for polarizing activity, MacCabe and Parker (1976) showed that there was a gradient in polarizing activity across the AP axis of the limb with the ZPA as the high point. Tickle et al. (1975) calculated that the type of gradient proposed by the above model would have to be set up in approximately 10 hours across a distance of $500-1000 \mu \mathrm{m}$, which makes diffusion a viable proposition. Furthermore, Summerbell (1979) placed an impermeable barrier along the AP axis in stage 16-19 and 21-22 wing buds. He found that if the barrier divided the AER, skeletal development occurred mainly on one side of the barrier. These results are consistent with the hypothesis that a diffusible morphogenic substance is emanating from the ZPA.

An obvious candidate for the morphogen is RA. Tickle et al. (1985) found that the release of RA by beads implanted in the anterior set up an exponential AP gradient. They calculated the threshold concentrations required to specify each digit. Based on these calculations, they showed that posterior implants gave anterior concentrations high enough to specify an additional digit II. However, in this case, the digit pattern is normal. The authors propose that cells may require an anisotropic retinoid distribution in their immediate environment in order to specify digits. The concentrations of RA detected by Thaller and Eichele (1987) in the limb were, in general, much higher than those proposed above. The diffusive properties of RA have been studied and it has been shown that limb tissue degrades RA (for review see Eichelle, 1989).

Under this hypothesis, removal of cells from the ZPA or treatment with $\gamma$ radiation would reduce the number of morphogen-producing cells, decreasing the value of $S_{0}$ and hence of morphogen in the limb. Thus, some threshold values may not be attained and the digits they define would be absent. This is in agreement with the experimental observations mentioned in Section III,A. 


\section{Mathematical Formulation}

This model may be formulated mathematically as follows (Summerbell and Lewis, 1975): Consider a cell lineage which is initially a mean distance $l$ from the distal tip of the limb. After some time, this lineage will have moved to a distance $x$ from the tip, due to distal growth. If each lineage has undergone $\tau$ mitotic doublings, then $x=1.2^{\tau}$. If $P(l, \tau)$ is PD positional value, then the above assumptions imply that

$$
\frac{\partial P}{\partial \tau}=\phi(x)=\phi\left(l .2^{\tau}\right)
$$

where $\phi(x)$ is zero except for small values of $x$, that is, positional value changes only inside the progress zone. Assuming that the progress zone has width $w$, that $\phi=\phi_{0}$ is constant for $x<w$, and that initially the whole outgrowth is contained within the progress zone and has zero positional value, Eq. (5) may be solved to give

$$
P(l, \tau)= \begin{cases}\phi_{0} \tau, & \text { for } l .2^{\tau}<w \\ \phi_{0} \log _{2} \frac{w}{l}, & \text { for } l .2^{\tau}>w\end{cases}
$$

If the proximal end of an element is specified by positional value $P_{1}$ and its distal end by $P_{2}$, then this model predicts that the length of the element would be

$$
w\left(2^{-P_{1} / \phi_{0}}-2^{-P_{2} / \phi_{0}}\right) 2^{\tau}
$$

that is, the length of the element at a particular stage is proportional to the size of the progress zone. Notice also that

$$
\phi_{0}=\frac{d P}{d \tau}=\frac{d P}{d t}\left(\frac{d \tau}{d t}\right)^{-1}
$$

for $x<w$, so that $\phi_{0}$ is the rate of change of positional value divided by the growth rate. If the rate of change of positional value was independent of the growth rate, it would be possible to change $\phi_{0}$ by changing the growth rate through varying the temperature, and thus change the length of the element. However, this does not happen, suggesting that the rate of change of positional value is dependent on the growth rate.

\section{Critique of the Model}

The progress zone model predicts that removal of the AER will halt the increase in positional value and will thus lead to distal truncation. This is observed to occur experimentally (Saunders, 1948). The model also makes 
Gierer and Meinhardt, 1972; Thomas, 1975; Schnakenberg, 1979; Murray, 1981a,b; Meinhardt, 1982) and for different types of boundary conditions, namely, Dirichlet, Neumann, or mixed. The Dirichlet problem corresponds to the case where the boundary is a source (or sink) of chemical, the Neumann problem corresponds to the case where the boundary is impermeable to the reactants. To illustrate the analysis we shall assume Neumann conditions, that is, $\mathbf{n} \cdot \nabla u_{\mathrm{i}}=0, i=1,2, \mathbf{x} \in \partial \Omega$ where $\partial \Omega$ is the boundary of the domain $\Omega$ and $\mathbf{n}$ is the outward normal (for full details see Othmer et al., 1990).

The spatially uniform steady states of the system given by Eqs. (9) and (10) are solutions $\left(u_{1}^{\mathrm{s}}, u_{2}^{\mathrm{s}}\right)$ of the equations

$$
f\left(u_{1}, u_{2}\right)=g\left(u_{1}, u_{2}\right)=0
$$

To analyze the linear stability of such a solution we linearize the system about the uniform steady state $\left(u_{1}^{\mathrm{s}}, u_{2}^{\mathrm{s}}\right)$ and look for solutions of the form

where

$$
\left(u_{1}, u_{2}\right)=\sum_{n} e^{\sigma t} \phi_{n}(\mathbf{x})
$$

$$
\begin{aligned}
\nabla^{2} \phi_{n} & =-\alpha_{n}^{2} \phi_{n}, \mathbf{x} \in \Omega \\
\mathbf{n} \cdot \nabla \phi_{n} & =0, \text { on } \partial \Omega
\end{aligned}
$$

and $\left(u_{1}, u_{2}\right)$ are now deviations from the uniform steady state $\left(u_{1}^{\mathrm{s}}, u_{2}^{\mathrm{s}}\right)$. The growth rate $\sigma$ is given by

$$
\operatorname{det}\left(K-\alpha_{n}^{2} D-\sigma I\right)=0
$$

where

$$
K=\left(\begin{array}{ll}
f_{\mathrm{u}_{1}} & f_{u_{2}} \\
g_{u_{1}} & g_{u_{2}}
\end{array}\right), \quad D=\left(\begin{array}{cc}
D_{1} & 0 \\
0 & D_{2}
\end{array}\right)
$$

The subscripts in $K$ represent partial derivatives and the functions are evaluated at the steady state.

Equation (13) shows that the spatial component of Eq. (12) is given by the eigenfunctions of the Laplacian on the domain $\Omega$. If, for example, one has the rectangular domain $\left[0, L_{1}\right] \times\left[0, L_{2}\right]$, then

$$
\phi_{n, m}=\mathbf{a} \cos \frac{n \pi}{L_{1}} x \cos \frac{m \pi}{L_{2}} y
$$

where

$$
\left(\frac{n \pi}{L_{1}}\right)^{2}+\left(\frac{m \pi}{L_{2}}\right)^{2}=\alpha_{n m}^{2}
$$


above, and showed that it can produce the desired sequence of pattern in a fashion similar to the classical Turing-type models.

\section{Mechanochemical Models}

\section{Hypotheses}

A fundamentally different biological approach to pattern formation is that of Oster, Murray, and co-workers (Oster et al., 1983, 1985; Murray et al., 1988). They propose that it is the mechanochemical interactions of cells with their external environment-the ECM - that is important in skeletal development. A particular mechanochemical model (Oster et al., 1985 ) is based on the following observations (Toole, 1972). In the wing bud, between stages 22 and 24 there is a reduction of hyaluronic acid (HA) in the prechondrogenic core, coupled with an increase in the activity of the enzyme hyaluronidase (HAase), which degrades HA. The model proposes the following scenario: cells in the progress zone are covered in a coat of HA which prevents them from interacting with each other and with the ECM. As they emerge from the progress zone they begin to secrete HAase which degrades HA. This causes the osmotic collapse of the limb interior, bringing cells into closer contact with each other. This enables the traction forces exerted by cells to deform the ECM and to drag other cells toward them, leading to the formation of an aggregation of cells. Depending on the domain size and the strength of cell traction it is possible to form a spatial pattern of several cell aggregations. These aggregates could deform the limb into a paddle shape, leading to more complex aggregations. It is assumed that these aggregations will then differentiate into cartilage, although this is not specifically included in the model.

\section{Mathematical Formulation}

The mathematical formulation of this model consists of five equations: two equations to describe changes in cell and matrix density due to convective motion caused by cell traction; two equations to account for the production, degradation, and transport of the chemicals HA and HAase; and a force balance equation which accounts for the different forces acting in the cell-matrix milieu, specifically, cell traction, osmotic swelling pressure, and the visco-elasticity of the matrix. The detailed mathematical formulation may be found in Oster et al. (1985).

The mechanochemical model described above considers cell aggregation to occur due to the osmotic collapse of the ECM. Variants of the above model have been proposed wherein the ECM behaves passively and aggregation occurs due to active cell motion (Oster et al., 1983). The 
However, it appears that the regressing vasculature does not show the signs of injury or disruption that would be caused by such a process (Hallman et al., 1987).

\section{E. Differential Adhesion Model}

The differential adhesion model hypothesizes that certain morphogenetic patterns occur due to groups of mutually adhesive cells acquiring a configuration that maximizes their adhesive interactions, thus minimizing their total interfacial free energy. Cell sorting, for example, between two populations of cells may occur because one population has a greater mutual adhesive affinity than the other, thus the configuration for minimum interfacial energy will occur when the more adhesive population aggregates into one clump surrounded by the other cell population (see, e.g., Steinberg and Poole, 1981). Differential adhesion has been proposed as a mechanism for limb bud initiation and subsequent elongation (Heintzelman et al., 1978). Oono and Shinozaki (1989) presented a discrete model for cell condensation based on cell-cell adhesiveness. They showed that their model exhibited a condensation sequence similar to that observed in the developing limb.

So far there is no clear-cut evidence implicating cell sorting in limb bud patterning. Searls (1972) found that the ability of cartilage and limb mesenchyme cells to sort out occurs late relative to formation of the skeletal primordia. Similarly, the expression of the cell surface heparan sulfate proteoglycan syndecan, which is a high-affinity ECM receptor becomes reduced in the chondrogenic areas coincidentally with chondrogenesis (Solursh et al., 1990). In the case of muscle differentiation, neural celladhesion molecule (NCAM) expression is clearly modulated (Knudsen $e t$ al., 1990) and can regulate myogenesis (Dickson et al., 1990). However, a role in tissue patterning in the limb has not yet been demonstrated. In some systems, the composition of the ECM itself can promote tissue segregation (Armstrong and Armstrong, 1990).

\section{F. Polar Coordinate Model}

So far we have discussed models which mainly address the process of normal development in the limb. The polar coordinate, or intercalation model (French et al., 1977), specifically addresses regulation in the limb as a result of surgical intervention. This model assumes that when normally nonadjacent cells are brought into contact with each other, resulting in a discontinuity in positional information, their interaction leads to the generation of cells with new positional values so that the discontinuity is 
accordingly. The spatial patterns predicted by the MC models, from linear analysis, are essentially the eigenfunctions of the Laplacian and thus similar to those predicted by RD models. In fact, it can be shown that the HA model can be approximated, in one dimension, to a pair of RD equations where the "reactants" are, respectively, HAase and strain. In higher space dimensions, the tensor form of the MC equations may lead to a richer family of structures than that exhibited by RD models. This, however, has yet to be fully analyzed. Thus, at the moment, there is no way to distinguish mathematically between MC and RD models. For example, they both predict the loss of digits if limb bud width is decreased due to a decrease in cell number. This prediction agrees with experimental observation (Alberch and Gale, 1983).

Another similarity between RD and MC models lies in the interpretation of their pattern-forming properties. In RD systems, one chemical may be termed an activator, the other an inhibitor. If the inhibitor diffuses more quickly than the activator then it is possible to attain a situation in which there is a pool of activator surrounded by a ring of inhibitor. This forces areas of high activator concentration to be separated, hence a heterogeneous spatial pattern in chemical concentrations arises. This is the well known "short-range activation, long-range inhibition" interpretation of pattern formation in RD systems (Segel and Jackson, 1972). In the MC models cell traction may be thought of as the short-range activation force and matrix elasticity as the longer range inhibition force. A cell aggregate is localized by the matrix elasticity opposing the traction produced by the aggregate so that other aggregates may be set up by the action of local traction forces and not be influenced by cell aggregates some distance away.

Both RD and MC models predict that the complexity and form of spatial pattern is largely dependent on scale and on boundary conditions. The MC models provide a mechanism by which the precartilage aggregates may deform the shape of the limb resulting in shape changes that lead to bifurcation into more complex aggregates appropriate for the more intricate distal limb structures (Oster et al., 1983). Reaction-diffusion models do not address the issue of limb shape changes.

As mentioned in Section V,D, 3 it has been shown that a recombination of two anterior stage $20 \mathrm{limb}$ halves forms two humeral elements (Wolpert, 1989; Wolpert and Hornbruch, 1990). The width of the recombinant limb in this case is the same as the normal limb, which only develops one humerus. This result cannot easily be explained by the above models and suggests that differentiation occurs at a much earlier stage than previously believed. Studies on the effects of the boundary both support and contradict the above models. Hurle et al. (1989) induced the formation of super- 
1. The initiation of the site of limb outgrowth and the determination of its polarity has received little theoretical attention. The mechanism which determines the limb site endows that tissue with special properties which may be important for subsequent development and provide clues to the underlying mechanisms involved in the processes that have been studied in more detail from a theoretical viewpoint. This possibility warrants detailed theoretical study of the initiation of the limb site.

2. Initially the myoblasts are spread uniformly throughout the limb bud but prior to cartilage formation they move to the DV periphery. At the same time (Chevallier et al., 1977; Christ et al., 1977), the precartilage cells sort out into the core of the limb bud. In vitro experiments show that myoblasts and chondroblasts can sort out in culture without the presence of ectoderm (Swalla and Solursh, 1986; Schramm and Solursh, 1990). In such cases, one sees small groups of myoblasts rather than the large masses that occur in vivo. Thus, although these cells may have the intrinsic property to sort out independently of ectoderm, the latter may be a global control, leading to a small number of large condensations rather than a large number of small condensations.

Experiments (Geduspan and MacCabe, 1987, 1989) suggest that the control of DV polarity resides in the mesoderm until about stage 14, and that during stages 14-16 it passes to the ectoderm. Inversion of DV ectoderm at stage 16 can lead to DV inversion of distal structures such as the muscle masses and the cartilage elements.

There are two established mechanisms that can produce cell sorting in general-differential chemotaxis, wherein one cell type responds to a chemoattract while the other does not, and differential adhesion. Based on in vitro studies many agents can provide a chemotactic stimulus depending on whether appropriate receptors are present on a specific cell type. For example, some ECM molecules or fragments such as fibronectin (Albini $e t$ al., 1987), laminin (Graf et al., 1987), and collagen (Kleinman et al., 1981) can serve as chemoattractants, as can many growth factors (see, e.g., Heldin et al., 1985). There is also evidence that early limb myoblasts behave chemotactically (Venkatasubramanian and Solursh, 1984). It has been shown that leg and flank tissue have different relative cohesiveness and this has been proposed as a mechanism for limb bud initiation and subsequent elongation (Heintzelman et al., 1978).

Thus, two possible scenarios for cell sorting are, first, chemotaxis, with the DV boundary being a source or a sink of chemoattractant. Second, differential adhesion, with the DV ectoderm being a source of a chemical that changes the adhesive properties of one of the cell types through, perhaps, interaction with the ECM. These scenarios will give rise to different mathematical formulations and thus, perhaps, to different pre- 
The scenario outlined above suggests that the cell sorting process is independent of the skeletal patterning process. However, the two processes may be coupled by assuming that the chemicals that are involved in cell sorting affect the patterning process or vice versa.

4. None of the above models fully address the process of differentiation. The observation that each skeletal element is of the same size when it is first observed (Summerbell, 1976) is formally consistent with some of the models discussed in Section V. From a RD viewpoint, it can be argued that cells require exposure to a certain threshold amount of chemical in order to differentiate, and that this threshold may be attained when the chemical prepattern reaches a critical length. The MC models would interpret this volume as being the critical cell volume density necessary for cell differentiation. Both these alternatives should be analyzed rigorously with a view toward determining whether either or both mechanisms are plausible.

In this chapter, we have reviewed pattern formation during early limb development from both experimental and theoretical viewpoints. Currently, rapid progress is being made by the application of molecular approaches. Exciting new findings demonstrate that at the very early stages of limb development, several molecules or their messages (for example, DNA binding proteins or bioactive agents) are present and are distributed in a graded fashion. It is not yet known how these gradients are set up nor what their precise role is in subsequent development. The role of future theoretical modeling will be to incorporate these findings into mathematical models in order to make testable predictions that might increase an understanding of how interactions at a molecular level combine to form the macroscopic patterns observed in the limb.

\section{ACKNOWLEDGMENT}

This material is based on work supported by the National Science Foundation under Grant No. DMS8901388 (P. K. M.) and HD05505 (M. S. and P. K. M. award to M. S.). P. K. M. would like to thank Professor H. Othmer, Department of Mathematics, University of Utah, for helpful discussions and financial support under National Institutes of Health Grant No. GM29123 (award to Othmer) and Dr. J. Geduspan and C. Schramm, Department of Biology, University of Iowa, for helpful discussions.

\section{REFERENCES}

Ahrens, P. B., Solursh, M., and Reiter, R. S. (1977). Dev. Biol. 60, 69-82.

Ahrens, P. B., Solursh, M., Reiter, R. S., and Singley, C. T. (1979). Dev. Biol. 69, 436-450.

Alberch, P., and Gale, E. A. (1983). J. Embryol. Exp. Morphol. 76, 177-197. 
Feinberg, R., and Beebe, D. (1983). Science 220, 1177-1179.

Feinberg, R. N., Latker, C. H., and Beebe, D. C. (1986). Anat. Rec. 214, 405-409.

Fell, H. B., and Canti, R. G. (1934). Proc. R. Soc. London, Ser. B 116, 316-349.

Franzen, A., Heinegard, D., and Solursh, M. (1987). Differentiation 36, 199-210.

Fraser, B. A. (1986). Acta Anat. 125, 142-144.

French, V., Bryant, P. J., and Bryant, S. V. (1977). Science 193, 969-981.

Frenz, D. A., Jakaria, N. S., and Newman, S. A. (1989). Dev. Biol. 136, 97-103.

Frenz, D. A., Akiyama, S. K., Paulsen, D. F., and Newman, S. A. (1989). Dev. Biol. 136, 87-96.

Gardiner, D. M., and Bryant, S. V. (1989). J. Exp. Zool. 251, 47-55.

Geduspan, J. S., and MacCabe, J. A. (1986). Am. Zool. 26, 13A.

Geduspan, J. S., and MacCabe, J. A. (1987). Dev. Biol. 124, 398-408.

Geduspan, J. S., and MacCabe, J. A. (1989). Anat. Rec. 224, 79-87.

Geduspan, J. S., and Solursh, M. (1990). Anat. Rec. 226, 35A.

Gehring, W. J. (1987). Science 236, 1245-1252.

Gierer, A., and Meinhardt, H. (1972). Kybernetik 12, 30-39.

Gould, R. P., Day, A., and Wolpert, L. (1972). Exp. Cell Res. 72, 325-336.

Graf, J., Iwamoto, Y., Sasaki, M., Martin, G. R., Kleinman, H. K., Robey, F. A., and Yamada, Y. (1987). Cell 48, 989-996.

Gregg, B. C., Rowe, A., Brickell, P. M., and Wolpert, L. (1989). Development 105, 769-777.

Hallman, R., Feinberg, R. N., Latker, C. H., Sasse, J., and Risau, W. (1987). Differentiation 34, 98-105.

Hamburger, V., and Hamilton, H. L. (1951). J. Morphol. 88, 49-92.

Harrison, R. (1918). J. Exp. Zool. 25, 413-461.

Heintzelman, K. F., Phillips, H. M., and Davis, G. S. (1978). J. Embryol. Exp. Morphol. 47, $1-15$.

Heldin, C. H., Wasteson, A., and Westermark, B. (1985). Mol. Cell. Endocrinol. 39, 169187.

Henry, D. (1981). "Geometric Theory of Semilinear Parabolic Equations," Lecture Notes in Biomathematics, Vol. 840. Springer-Verlag, Berlin.

Hill, R., Jones, P., Rees, A., Sime, C., Justice, M., Copeland, N., Jenkins, N., Graham, E., and Davidson, D. (1989). Genes Dev. 3, 26-37.

Hinchliffe, J. R., and Johnson, D. R. (1980). "The Development of the Vertebrate Limb." Oxford Univ. Press, London.

Hornbruch, A., and Wolpert, L. (1970). Nature (London) 226,764-766.

Hornbruch, A., and Wolpert, L. (1986). J. Embryol. Exp. Morphol. 94, 257-266.

Horton, W. E., Jr., Higginbotham, J. D., and Chandrasekhar, S. (1989). J. Cell. Physiol. 141, $8-15$.

Hurle, J. M., and Gañan, Y. (1986). J. Embryol. Exp. Morphol. 94, 231-244.

Hurle, J. M., and Gañan, Y. (1987). Anat. Embryol. 176, 393-399.

Hurle, J. M., Gañan, Y., and Macias, D. (1989). Dev. Biol. 132, 368-374.

Ide, H., and Aono, H. (1988). Dev. Biol. 130, 767-773.

Inoue, H., Kato, Y., Iwamoto, M., Hiraki, Y., Sakuda, M., and Suzuki, F. (1989). J. Cell. Physiol. 138, 329-337.

Iten, L. E., and Murphy, D. J. (1980). Dev. Biol. 75, 373-385.

Iten, L. E., Murphy, D. J., and Javois, L. C. (1981). J. Exp. Zool. 215, 103-106.

Joyce, M. E., Roberts, A. B., Sporn, M. B., and Bolander, M. E. (1990). J. Cell Biol. 110, 2195-2207.

Kastner, P. H., Krust, A., Mendelsohn, C., Garnier, J. M., Zelent, A., Leroy, P., Staub, A., and Chambon, P. (1990)., Proc. Natl. Acad. Sci. U.S.A. 87, 2700-2704. 
Osdoby, P., and Caplan, A. I. (1979). Dev. Biol. 73, 84-102.

Osdoby, P., and Caplan, A. I. (1980). Calcif. Tissue Int. 30, 43-50.

Oster, G. F., Murray, J. D., and Harris, A. K. (1983). J. Embryol. Exp. Morphol. 78, 83-125. Oster, G. F., Murray, J. D., and Maini, P. K. (1985). J. Embryol. Exp. Morphol. 89, 93-112.

Othmer, H. G. (1986). J. Theor. Biol. 121, 505-508.

Othmer, H. G., Dillon, R., and Maini, P. K. (1990). In preparation.

Paulsen, D. F., and Lang, L. (1990). Anat. Rec. 226, 78A.

Paulsen, D. F., Langille, R. M., and Solursh, M. (1988). Anat. Rec. 220, 74A.

Perelson, A. S., Maini, P. K., Murray, J. D., Hyman, J. M., and Oster, G. F. (1986). J. Math. Biol. 24, 525-541.

Reiter, R. S. and Solursh, M. (1982). Dev. Biol. 93, 28-35.

Robert, B., Sassoon, D., Jacq, B., Gehring, W., and Buckingham, M. (1989). EMBO J. 8, 91-100.

Rowe, D., and Fallon, J. (1982). J. Embryol. Exp. Morphol. 68, 1-7.

Ruberte, E., Dollé, P., Krust, A., Zelent, A., Morriss-Kay, G., and Chambon, P. (1990). Development 108, 213-222.

Rubin, L., and Saunders, J. W., Jr. (1972). Dev. Biol. 28, 94-112.

Rudnick, D. (1945). J. Exp. Zool. 100, 1-17.

Sasse, J., Horwitz, A., Pacifici, M., and Holtzer, H. (1984). J. Cell Biol. 99, 1856-1866.

Saunders, J. W., Jr. (1948). J. Exp. Zool. 108, 363-403.

Saunders, J. W., Jr. (1977). In "Vertebrate Limb and Somite Morphogenesis" (D. A. Ede, J. R. Hinchliffe, and M. Balls, eds.), pp. 215-228. Cambridge Univ. Press, London.

Saunders, J. W., Jr., and Gasseling, M. T. (1963). Dev. Biol. 7, 64-78.

Saunders, J. W., Jr., and Gasseling, M. T. (1968). In "Epithelial-Mesenchymal Interactions"' (R. Fleischmajer and R. E. Billingham, eds.), pp. 78-97. Williams \& Wilkins, Baltimore, Maryland.

Saunders, J. W., Jr., and Gasseling, M. T. (1983). Prog. Clin. Biol. Res. 110A 67-76.

Saunders, J. W., Jr., Gasseling, M. T., and Cairns, J. M. (1955). Nature (London) 175, 673-674.

Saunders, J. W., Jr., Gasseling, M. T., and Gfeller, M. D. (1958). J. Exp. Zool. 137, 39-74.

Saunders, J. W., Jr., Gasseling, M. T., and Cairns, J. M. (1959). Dev. Biol. 1, 281-301.

Schmid, T. M., and Lisenmayer, T. F. (1985). Dev. Biol. 107, 373-381.

Schnakenberg, J. (1979). J. Theor. Biol. 81, 389-400.

Schramm, C., and Solursh, M. (1990). Anat. Embryol. 82, 235-247.

Searls, R. L. (1965). Dev. Biol. 11, 155-168.

Searls, R. L. (1967). J. Exp. Zool. 166, 39-50.

Searls, R. L. (1968). Dev. Biol. 17, 382-399.

Searis, R. L. (1972). Exp. Cell Res. 73, 57-64.

Searls, R. L., and Janners, M. Y. (1969). J. Exp. Zool. 170, 365-376.

Searls, R. L., and Janners, M. Y. (1971). Dev. Biol. 24, 198-213.

Seed, J., Olwin, B. B., and Hauschka, S. D. (1988). Dev. Biol. 128, 50-57.

Segel, L. A., and Jackson, J. L. (1972). J. Theor. Biol. 37, 545-559.

Shellswell, G. B., and Wolpert, L. (1977). In "Vertebrate Limb and Somite Morphogenesis", (D. A. Ede, J. R. Hinchliffe, and M. Balls, eds.), pp. 71-86. Cambridge Univ. Press, London.

Shinomura, T., and Kimata, K. (1990). Dev. Growth Differ. 32, 243-248.

Shinomura, T., Jensen, K. L., Yamagata, M., Kimata, K., and Solursh, M. (1990). Anat. Embryol. 181, 227-233.

Shoaf, S. A., Conway, K., and Hunt, R. K. (1984). J. Theor. Biol. 109, 299-329.

Singley, C. T., and Solursh, M. (1981). Dev. Biol. 84, 102-120. 
Turing, M. A. (1952). Philos. Trans. R. Soc. London, Ser. B 237, 37-73.

Venkatasubramanian, K., and Solursh, M. (1984). Dev. Biol. 104, 428-433.

Von der Mark, K., and Kuhl, U. (1985). Biochim. Biophys. Acta 823, 147-160.

Von der Mark, K., and Ocalan, M. (1989). Differentiation 40, 150-157.

Wachtler, F., Christ, B., and Jacob, H. J. (1981). Anat. Embryol. 161, 282-289.

Wilson, D. J. (1986). Differentiation 30, 183-187.

Wilson, D. J., and Hinchliffe, J. R. (1987). Development 99, 99-108.

Wolpert, L. (1969). J. Theor. Biol. 25, 1-47.

Wolpert, L. (1981). Morphog. Pattern Form. Proc. Symp., Ann Arbor, Mich. pp. 5-20.

Wolpert, L. (1989). In "Cell to Cell Signalling: From Experiments to Theoretical Models" (A. Goldbeter, ed.), pp. 133-144. Academic Press, London.

Wolpert, L., and Hornbruch, A. (1981). J. Embryol. Exp. Morphol. 63, 145-159.

Wolpert, L., and Hornbruch, A. (1987). Development 100,338.

Wolpert, L., and Hornbruch, A. (1990). Development 109, 961-966.

Wolpert, L., Lewis, J., and Summerbell, D. (1975). Ciba Found. Symp. 29, 95-130.

Zanetti, N. C., and Solursh, M. (1984). J. Cell Biol. 99, 115-123.

Zanetti, N. C., and Solursh, M. (1986). Dev. Biol. 113, 110-118.

Zanetti, N. C., and Solursh, M. (1989). In "Cell Shape: Determinants, Regulation and Regulatory Role" (W. D. Stein and F. Bonner, eds.), pp. 291-327. Academic Press, San Diego, California.

Zanetti, N. C., Dress, V. M., and Solursh, M. (1990). Dev. Biol. 139, 383-395.

Zwilling, E. (1955). J. Exp. Zool. 128, 423-441.

Zwilling, E. (1956a). J. Exp. Zool. 132, 173-187.

Zwilling, E. (1956b). J. Exp. Zool. 132, 241-253.

Zwilling, E. (1961). Adv. Morphog. 1, 301-330.

Zwilling, E., and Hansborough, L. A. (1956). J. Exp. Zool. 132, 219-239. 
Smith, J. C. (1979). J. Embryol. Exp. Morphol. 52, 105-113.

Smith, J. C., and Wolpert, L. (1981). J. Embryol. Exp. Morphol. 63, 127-144.

Smith, J. C., Tickle, C., and Wolpert, L. (1978). Nature (London) 272, 612-613.

Solursh, M. (1984a). Symp. Soc. Dev. Biol. 42, 277-304.

Solursh, M. (1984b). Cell Differ. 15, 554-557.

Solursh, M. (1990). Semin. Dev. Biol. 1, 45-53.

Solursh, M., and Jensen, K. L. (1988). Development 104, 41-50.

Solursh, M., and Reiter, R. (1980). Dev. Biol. 78, 141-150.

Solursh, M., and Reiter, R. S. (1988). J. Exp. Zool. 248, 147-154.

Solursh, M., Singley, C. T., and Reiter, R. S. (1981). Dev. Biol. 86, 471-482.

Solursh, M., Linsenmayer, T. F., and Jensen, K. L. (1982). Dev. Biol. 94, 259-264.

Solursh, M., Jensen, K. L., Zanetti, N. C., Lisenmayer, T. F., and Reiter, R. S. (1984). Dev. Biol. 105, 451-457.

Solursh, M., Drake, C., and Meier, S. (1987). Dev. Biol. 121, 389-396.

Solursh, M., Reiter, R. S., Jensen, K. L., Kato, M., and Bernfield, M. (1990). Dev. Biol. 140, 83-92.

Stark, R., and Searls, R. (1973). Dev. Biol. 33, 138-153.

Stark, R., and Searls, R. (1974). Dev. Biol. 38, 51-63.

Steinberg, M. S., and Poole, T. J. (1981). Philos. Trans. R. Soc. London, Ser. B 295, 451-460.

Stirpe, N. S., and Goetnick, P. F. (1989). Development 107, 23-33.

Stocker, K. M., and Carlson, B. M. (1990). Wilhelm Roux's Arch. Dev. Biol. 198, 371-381.

Summerbell, D. (1974a). J. Embryol. Exp. Morphol. 32, 227-237.

Summerbell, D. (1974b). J. Embryol. Exp. Morphol. 32, 651-660.

Summerbell, D. (1976). J. Embryol. Exp. Morphol. 35, 241-260.

Summerbell, D. (1977). J. Embryol. Exp. Morphol. 41, 137-159.

Summerbell, D. (1979). J. Embryol. Exp. Morphol. 50, 217-233.

Summerbell, D. (1981). J. Embryol. Exp. Morphol. 63, 161-180.

Summerbell, D., and Lewis, J. H. (1975). J. Embryol. Exp. Morphol. 33, 621-643.

Suzuki, H. R., and Ide, H. (1987). Dev. Biol. 124, 41-49.

Swalla, B. J., and Solursh, M. (1984). Differentiation 26, 42-48.

Swalla, B. J., and Solursh, M. (1986). Dev. Biol. 116, 31-38.

Swalla, B. J., Owens, E. M., Linsenmayer, T. F., and Solursh, M. (1983). Dev. Biol. 97, 59-69.

Sweeny, L. J., Kennedy, J. M., Zak, R., Kokjohn, K., and Kelley, S. W. (1989). Dev. Biol 133, 361-374.

Swiderski, R. E., and Solursh, M. (1990). Dev. Biol. 140, 73-82.

Thaller, C., and Eichele, G. (1987). Nature (London) 327, 625-628.

Thaller, C., and Eichele, G. (1990). Nature (London) 345, 815-822.

Thomas, D. (1975). In "Analysis and Control of Immobilized Enzyme Systems" (D. Thomas and J. P. Kernevez, eds.), pp. 115-150, Springer.

Thorogood, P., and Hinchliffe, J. R. (1975). J. Embryol. Exp. Morphol. 33, 581-606.

Tickle, C. (1981a). Nature (London) 289, 295-298.

Tickle, C. (1981b). In "Development in Animals" (M. H. Johnson, ed.), pp. 101-136. Elsevier/North-Holland, New York.

Tickle, C. (1983). Prog. Clin. Biol. Res. 110A 89-98.

Tickle, C., Summerbell, D., and Wolpert, L. (1975). Nature (London) 254, 199-202.

Tickle, C., Alberts, B., Wolpert, L., and Lee, J. (1982). Nature (London) 296, 564-566.

Tickle, C., Lee, J., and Eichele, G. (1985). Dev. Biol. 109, 82-95.

Todt, W. L., and Fallon, J. F. (1984). J. Embryol. Exp. Morphol. 80, 21-41.

Toole, B. (1972). Dev. Biol 29, 321-329. 
Kauffman, S. A., Shymko, R. M., and Trabert, K. (1978). Science 199, 259-270.

Kieny, M. (1977). In "Vertebrate Limb and Somite Morphogenesis" (D. A. Ede, J. R. Hinchliffe, and M. Balls, eds.), pp. 215-228. Cambridge Univ. Press, London.

Kleinman, H. K., Klebe, R. J., and Martin, G. (1981). J. Cell Biol. 88, 473-485.

Knudsen, K. A., McElwee, S. A., and Myers, L. (1990). Dev. Biol. 138, 159-168.

Knudson, C. B. and Toole, B. P. (1987). Dev. Biol. 124, 82-90.

Knudson, C. B. and Toole, B. P. (1988). Biochem. Int. 17, 735-745.

Kosher, D. M., Penney, J. D., and Hickey, T. (1984). Cell Differ. 14, 213-221.

Kosher, R. A. Walker, K. H., and Ledger, P. W. (1982). Cell Differ. 11, 217-228.

Krabbenhoft, K. M., and Fallon, J. F. (1989). Dev. Biol. 131, 337-382.

Kuhl, U., Timpl, R., and Von Der Mark, K. (1982). Dev. Biol. 93, 344-354.

Kuhl, U., Ocalan, M., Timpl, R., and Von Der Mark, K. (1986). Dev. Biol. 117, 628-635.

Kulyk, W. M., and Kosher, R. A. (1987). Dev. Biol. 120, 535-541.

Kulyk, W. M., Rodgers, B. J., Greer, K., and Kosher, R. A. (1989a). Dev. Biol. 135, 424-430.

Kulyk, W. M., Upholt, W. B., and Kosher, R. A. (1989b). Development 106, 449-455.

Latker, C. H., Feinberg, R. N., and Beebe, D. C. (1986). Anat. Rec. 214, 410-417.

Lee, J., and Tickle, C. (1985). J. Embryol. Exp. Morphol. 90, 139-169.

Lewis, J. H. (1975). J. Embryol. Exp. Morphol. 33, 419-434.

Lewis, J. H. (1977). In "Vertebrate Limb and Somite Morphogenesis" (D. A. Ede, J. R. Hinchliffe, and M. Balls, eds.), pp. 215-228. Cambridge Univ. Press, London.

Lyons, K. M., Pelton, R. W., and Hogan, B. L. M. (1989). Genes Dev. 3, 1657-1668.

Lyons, K. M., Pelton, R. W., and Hogan, B. L. M. (1990). Development 109, 833-844.

MacCabe, A. B., Gasseling, M. T., and Saunders, J. W., Jr. (1973). Mech. Ageing Dev. 2, $1-12$.

MacCabe, J. A., and Parker, B. W. (1976). Dev. Biol. 54, 297-303.

Maden, M., Ong, D. E., Summerbell, D., and Chytil, F. (1988). Nature (London) 335, 733-735.

Mangelsdorf, D. J., Ong, E. S., Dyck, J. A., and Evans, R. M. (1990). Nature (London) 345, 224-229.

Martin, P., and Lewis, J. (1986). Dev. Biol. 118, 233-246.

Meinhardt, H. (1982). "Models of Biological Pattern Formation." Academic Press, London.

Munaim, S. I., Klagsbrun, M., and Toole, B. P. (1988). Proc. Natl. Acad. Sci. U.S.A. 85, 8091-8093.

Muneoka, K., Bryant, S. V., and Gardiner, D. M. (1989). In "Growth Control in Limb Regeneration" (J. Armstrong and G. Malacinski, eds.), pp. 143-156. Oxford Univ. Press, New York.

Murray, J. D. (1981a). Philos. Trans. R. Soc. London, Ser. B 295, 473-496.

Murray, J. D. (1981b). J. Theor. Biol. 88, 161-199.

Murray, J. D., Maini, P. K., and Tranquillo, R. T. (1988). Phys. Rep. 171, 59-84.

Nagorcka, B. N. (1989). J. Theor. Biol. 137, 127-162.

Newman, S. A., and Frisch, H. L. (1979a). Science 205, 662-668.

Newman, S. A., and Frisch, H. L. (1979b). Science 205, 1337.

Newman, S. A., Frish, H. L., and Percus, J. K. (1988). J. Theor. Biol. 134, 183-197.

Ocalan, M., Goodman, S. L., Kuhle, A., Hauschka, S., and Von der Mark, K. (1988). Dev. Biol. 125, 158-167.

Oliver, G., Wright, C., Hardwicke, J., and Robertis, E. D. (1988). Cell 55, 1017-1024.

Oliver, G., Sidell, N., Fiske, W., Heinzman, C., Mohandas, T., Sparkes, R., and Robertis, E. D. (1989). Genes Dev. 3, 641-650.

Olwin, B. B., and Hall, Z. W. (1985). Dev. Biol. 112, 359-367.

Oono, Y., and Shinozaki, A. (1989). Forma 4, 75-102 (1989). 
Albini, A., Allavena, G., Melchiori, A., Giancotti, F., Richter, H., Comoglio, P. M., Parodi, S., Martin, G. R., and Tarone, G. (1987). J. Cell Biol. 105, 1867-1872.

Allen, F., Tickle, C., and Warner, A. (1990). Development 108, 623-634.

Aono, H., and Ide, H. (1988). Dev. Biol. 128, 136-141.

Archer, C. W., Langille, R., Schramm, C., Teran, M. A. F., and Solursh, M. (1989). Am. Zool. 29, 162A.

Arcuri, P., and Murray, J. D. (1986). J. Math. Biol. 24, 141-165.

Armstrong, P. B., and Armstrong, M. T. (1990). J. Cell Biol. 110, 1439-1455.

Aulthouse, A. L., and Solursh, M. (1987). Dev. Biol. 120, 377-384.

Bowen, J., Hinchliffe, J. R., Horder, T. J., and Reeve, A. M. F. (1989). Anat. Embryol. 179, 269-283.

Bryant, S. V., and Gardiner, D. M. (1987). Am. Zool. 27, 675-696.

Bunow, B., Kernevez, J.-P., Joly, G., and Thomas, D. (1980). J. Theor. Biol. 84, 629-649.

Caplan, A. I. (1977). In "Vertebrate Limb and Somite Morphogenesis" (D. A. Ede, J. R. Hinchliffe, and M. Balls, eds.), pp. 199-213. Cambridge Univ. Press, London.

Caplan, A. I. (1985). Cell Differ. 16, 1-11.

Caplan, A. I., and Koutroupas, S. (1973). J. Embryol. Exp. Morphol. 29, 571-583.

Carrington, J. L., and Fallon, J. F. (1984). J. Exp. Zool. 232, 297-308.

Carrington, J. L., and Reddi, A. H. (1990). Exp. Cell Res. 186, 368-373.

Chaube, S. (1959). J. Exp. Zool. 140, 29-77.

Chevailler, A., and Kieny, M. (1982). Wilhelm Roux's Arch. Dev. Biol. 191, 277-280.

Chevallier, A., Kieny, M., and Mauger, A. (1977). J. Embryol. Exp. Morphol. 41, 245-258.

Chiquet, M., Eppenberger, H. M., and Turner, D. C. (1981). Dev. Biol. 88, 220-235.

Christ, B., Jacob, H. J., and Jacob, M. (1977). Anat. Embryol. 150, 187-206.

Cottrill, C. P., Archer, C. W., Hornbruch, A., and Wolpert, L. (1987a). Dev. Biol. 119, 143-151.

Cottrill, C. P., Archer, C. W., and Wolpert, L. (1987b). Dev. Biol. 122, 503-515.

Dessau, W., Von Der Mark, H., Von Der Mark, K., and Fischer, S. (1980). J. Embryol. Exp. Morphol. 57, 51-60.

Dickson, G., Peck, D., Moore, S. E., Barton, C. H., and Walsh, F. S. (1990). Nature (London) 344, 348-351.

DiCorleto, P. E., and Bowen-Pope, D. F. (1983). Proc. Natl. Acad. Sci. U.S.A. 80, 19191923.

Dollé, P., and Duboule, D. (1989). EMBO J. 8, 1507-1515.

Dollé, P., Izpisúa-Belmonte, J. C., Falkenstein, H., Renucci, A., and Duboule, D. (1989a). Nature (London) 342, 767-772.

Dollé, P., Ruberte, E., Kastner, P., Petkovich, M., Stoner, C. M., Gudas, L. J., and Chambon, P. (1989b). Nature (London) 342, 702-705.

Ede, D. A. (1971). Symp. Soc. Exp. Biol. 25, 235-254.

Ede, D. A., and Agerbak, G. S. (1968). J. Embryol. Exp. Morphol. 20, 81-100.

Ede, D. A., and Flint, O. P. (1972). J. Embryol. Exp. Morphol. 27, 245-260.

Ede, D. A., Flint, O. P., Wilby, O. K., and Colquhoun, P. (1977). In "Vertebrate Limb and Somite Morphogenesis" (D. A. Ede, J. R. Hinchliffe, and M. Balls, eds.), pp. 161-179. Cambridge Univ. Press, London.

Eichele, G. (1989). Trends Genet. 5, 246-251.

Eichele, G., Tickle, C., and Alberts, B. M. (1985). J. Cell Biol. 101, 1913-1920.

Fallon, J. F., and Crosby, G. M. (1975). Dev. Biol. 42, 24-34.

Fallon, J. F., and Crosby, G. M. (1977). In "Vertebrate Limb and Somite Morphogenesis", (D. A. Ede, J. R. Hinchliffe, and M. Balls, eds.), pp. 55-69. Cambridge Univ. Press, London. 
dictions. Comparison with experimental results may then help distinguish between the two scenarios.

The results of Lewis (1977) and Ahrens et al. (1979) suggest that there are several different cell types in the limb bud. The two main types of cell that have been studied are myoblasts and chondroblasts, but other cell types, such as differentiating perichondrium and perimyceum cells, may affect their pattern formation (Chevailler and Kieny, 1982). This is an important issue which has received little attention. By extending the above model to account for the interactions of more than two cell types, one may be able to gain insight into the possible effects that a third cell type may have on the sorting and differentiation of myoblasts and chondroblasts.

3. The next stage of the process is one of forming the skeletal pattern in the prechondrogenic core. Most of the models discussed in Section $\mathrm{V}$ have the ability to generate pattern from an initially homogeneous system. However, as we pointed out, none of them can fully account for the results of some experimental observations. Some experiments concerning regulation have produced conflicting and controversial results. To fully understand limb development it is essential to eliminate as many of these controversies as possible so that an agreed list of regulatory properties exhibited by the limb can be drawn up. The patterning mechanism would then have to exhibit these regulatory properties. It is apparent that although the models discussed above would satisfy several of the entries in such a list, they are too simple to satisfy all of them (see, e.g., Martin and Lewis, 1986; Wolpert, 1989; Wolpert and Hornbruch, 1990). Recent experimental observations suggest a hierarchy of control mechanisms wherein parameters in the above models, which have largely been assumed constant in the theory, vary in space and time and may themselves be the solutions of other models operating at a different level in the hierarchy. For example, the diffusion coefficients in the RD systems may vary due to the spatial and temporal differences in gap junction permeability (Allen et al., 1990) which may, in turn, be controlled by some other mechanism.

Several of the above models rely on domain size and shape changes to produce the observed sequence of pattern formation in the early limb. However, none of them fully addresses the mechanisms behind size and shape changes. The pattern may be laid down prior to gross morphological changes other than PD elongation. Thus, other changes-for example, bending at the elbow-may be secondary effects, perhaps the consequence of the skeletal pattern. Of the above models, only the MC models attempt to link the pattern-forming mechanism with domain shape changes. This remains to be analyzed in more detail. 
numerary cartilage elements by ectoderm removal, suggesting that the boundary conditions are important. However, Martin and Lewis (1986) removed the dorsal ectoderm by stage 23 and found that skeletal development was essentially normal.

All of the above models make a large number of predictions which are in agreement with experimental observations. However, there are some general drawbacks to them. For example, initial cell sorting between myoblasts and chondroblasts is ignored in all but the differential adhesion model. None of the models fully addresses the process of differentiation. The gradient model and the progress zone model are one-dimensional models of an essentially three-dimensional process (Bowen et al., 1989). Although several of the models use aspects of limb outgrowth and shape changes to generate pattern, none of them fully incorporate these effects. Only a few of the above models suggest possible mechanisms for limb outgrowth and shape changes.

None of the theoretical models proposed thus far have explicitly addressed the role of cell shape changes during differentiation. Shape changes would be implicit in the MC model after cell aggregation, but the form of the model does not enable one to address this issue precisely. The chemical prepatterning models may affect cell shape and cytoskeleton architecture, for example, through altering the type of contact the cell makes with the ECM. An important question is whether or not cell shape changes are a primary or secondary event.

\section{Concluding Remarks}

Each of the models discussed above addresses a particular aspect of the developmental program. This is an important first step toward an understanding of the sequence of developmental events in the chick limb. The eventual goal of the modeling is to piece together all the aspects and stages of development to arrive at a coherent theory of limb development. The theory must also be consistent with the results of surgical manipulations. In this section we briefly recall the main steps in the sequence of limb development, which were more fully presented in earlier sections, and discuss how theoretical models may help in elucidating the underlying mechanisms involved.

Pattern formation in the early limb appears to consist of four main stages (which may overlap): (1) the initiation of the limb site; (2) cell sorting; (3) spatial patterning in the prechondrogenic core, its growth and regulation; and (4) differentiation. We examine each stage in turn and outline the important theoretical and experimental questions that they suggest. 
smoothed out. This model can describe the results of experiments that are inconsistent with the gradient model (Iten and Murphy, 1980) but it is contradicted by other experiments (Wolpert, 1981). Although this model is widely used to describe the results of grafting and regeneration experiments in the cockroach limb and in the amphibian limb (Bryant and Gardiner, 1987), it has no molecular basis as yet, and a detailed mathematical formulation does not exist.

At the cell biological level this model suggests that there may be an underlying mechanism of growth control that is involved in limb pattern formation. The model predicts that cells with different positional values can recognize each other and in turn respond by increased cell proliferation (Muneoka et al., 1989). In fact, there is a demonstrable positiondependent growth stimulation in the newt limb (Gardiner and Bryant, 1989). Similarly in the chick limb bud, there is extensive growth when anterior and posterior quarters of the limb bud are combined in vitro compared to other combinations (Suzuki and Ide, 1987). The nature of such position-dependent interactions may provide important insights into patterning mechanisms.

\section{G. COMParison OF Models}

Although the gradient model and the RD models are based on a chemical prepattern, there is a fundamental difference between them. The application of the RD model to skeletal development assumes that cells will acquire equivalent positional values if the morphogen concentration lies above a certain threshold and will follow equivalent developmental pathways. This is fundamentally different from the assumption underlying the gradient model, in which cells respond to different threshold levels. In this case, cells must translate positional information into positional value in such a way that nonequivalent positional information is interpreted as equivalent in terms of differentiation so that cells at different positions follow the same developmental pathway. In the autopod, for example, under RD theory the digits are assumed to be similar, but under the gradient model they are intrinsically different (Nagorcka, 1989). Thus, under the hypotheses of RD theory, the complexity of the final pattern is contained in the prepattern, whereas, in the gradient model, the pattern that gives rise to positional information is simple, but its interpretation via positional value is where the complexity of pattern emerges. The mode of interpretation of the prepattern is unspecified in both models.

The mechanochemical (MC) models are fundamentally different, biologically, to the RD models because they propose that the spatial pattern that is set up is in cell density. The cells in these aggregates then differentiate 
equations that describe the mechanochemical models are much more complex than those describing RD systems and are not as amenable to mathematical analysis as the latter. Linear analysis of simplified versions of these models (similar to that outlined in Section V,C,2 for RD systems) shows that they are capable of generating spatially heterogeneous patterns from an initially homogeneous state. The results of linear theory have been verified by solving the full nonlinear system numerically (Perelson et al., 1986).

\section{Critique of the Model}

The major assumption underlying the mechanochemical models is that cell aggregation precedes cell differentiation. This has been observed experimentally but, as mentioned in Section IV,B, it is a controversial issue as to whether these aggregates are set up by cell motion, or by the collapse of the ECM, or whether such aggregates are merely artifacts of the fixing process used to observe the cells (Singley and Solursh, 1981; Aulthouse and Solursh, 1987; Searls, 1967).

Recently it has been shown that if two anterior stage 20 limb halves are combined, the recombinant forms two humeral elements (Wolpert, 1989; Wolpert and Hornbruch, 1990). This suggests that the anterior stage 20 limb half contains cells that have already differentiated, yet, at this stage, there is no visible aggregation of cells.

Retinoic acid affects the secretion of HA by cells in the mouse limb bud and alters limb development (Kosher et al., 1984). This is consistent with the assumption that HA plays a major role in chondrogenesis. Recently, however, HAase activity has been detected in stage 18 wing buds and observed to remain relatively constant throughout subsequent stages of development until stage 29 (Kulyk and Kosher, 1987). This contradicts the scenario in which $\mathrm{HA}$ is the glycosaminoglycan (GAG) proposed to play the prominent role. Of course, this does not rule out this type of model because such a scenario may still be realistic. In fact, Toole's recent work suggests the developmental regulation of cell surface receptor for HA. Early stage mesenchyme cells have an extensive HA-rich cell coat which interferes with cell aggregation. On the other hand, the cell coat is not present on the cells at the time of precartilage aggregate formation (Knudson and Toole, 1987, 1988).

Wilson (1986) proposed that the mechanochemical models may account for the observation that the vascular system becomes excluded from the prechondrogenic core prior to chondrogenesis. He proposed that the cell traction exerted by the prechondrogenic aggregates constrict and close off thin-walled undifferentiated vessels caught in the aggregation leading to the avascularity of the core. Thus, the vascular pattern may be a consequence of the cartilage differentiation, rather than the cause of it. 
$n$ and $m$ are integers and $\mathbf{a}$ is a constant dependent on initial conditions. These modes will have positive growth rate $\sigma$ if $\alpha_{n, m}^{2} \in\left(\mu_{-}, \mu_{+}\right)$, where

$$
\mu \pm=\frac{D_{1} g_{u_{2}}+D_{2} f_{u_{1}} \pm\left[\left(D_{1} g_{u_{2}}+D_{2} f_{u_{1}}\right)^{2}-4 D_{1} D_{2} \operatorname{det} K\right]^{1 / 2}}{2 D_{1} D_{2}}
$$

Thus, linear stability theory delimits regions in parameter space wherein a spatially uniform steady state becomes unstable to spatially nonuniform perturbations of the appropriate form. Note that as the domain becomes larger we can choose larger values of $n$ and $m$ to satisfy Eq. (17), that is, linear theory predicts more complex structure as domain size increases. It can be shown that if the steady state is linearly unstable, then it is also unstable for the full nonlinear system (see, e.g., Henry, 1981). The pattern to which the full nonlinear system evolves depends on the boundary conditions, the initial conditions and on the nonlinearities in $f$ and $g$ (Murray, 1981a; Arcuri and Murray, 1986).

\section{Critique of the Model}

This model has been applied to pattern formation in several biological systems (Kauffman et al., 1978; Meinhardt, 1982; Shoaf et al., 1984). However, RD systems frequently have multiple solutions, and solutions lack the degree of scale invariance and robustness under perturbations of the parameters or of the domain that is exhibited in developing systems (Bunow et al., 1980; Arcuri and Murray, 1986). The boundary is assumed to be homogeneous, but heterogeneity in the boundary is established before limb outgrowth begins, and certain regions on the limb periphery have already differentiated to form specialized signaling zones. Furthermore, the existence and the role of chemical morphogens has not yet been established. Recently it has been proposed that fibronectin and TGF- $\beta$ may be the morphogens in a RD system (Newman et al., 1988). Although these chemicals appear to have an effect on chondrogenesis, it has yet to be shown that they play a role in establishing the spatial pattern of chondrogenesis in normal limb development, rather than simply being a product of the process.

Newman and Frisch (1979a,b) postulated a RD model which consisted of only one chemical, and asserted that such a model could produce the sequence of condensations observed in the chick limb. This work has been cited several times in the literature as a possible mechanism for cell patterning in the limb. However, it has been shown by Othmer (1986) that such a model is too simple to generate the desired sequence of patterns. Hence, it is not a realistic model for limb development. Newman et al. (1988) presented a two-chemical RD model identical to those discussed 
certain predictions on the outcome of grafting a donor wing tip onto a host stump which agree closely with observation (Summerbell and Lewis, 1975). However, it does not have any regulative properties and thus cannot account for the immense capability of the early limb bud to regulate (Kieny, 1977). For example, removal of slices of the early limb bud perpendicular to the PD axis can lead to normal limbs (Summerbell, 1977). According to the progress zone model, such an experiment should result in deletions along the PD axis of the final pattern.

As in the case of the gradient model, this model accounts only for pattern along one dimension, and does not address the issue of differences along the AP axis. Of course, one may be able to combine both the above models in some way in order to derive a model which accounts for polarity along both the AP and the PD axis. For example, a cell's positional value might be determined by two coordinates, one corresponding to its interpretation of its position along the AP axis, the other to its interpretation of its position along the PD axis. Recently, Dolle et al. (1989a) proposed that both the AP and the PD axes could be specified through a single gradient of positional signaling emanating from the ZPA together with a temporal pattern of Hox gene expression during limb bud outgrowth.

\section{Reaction-Diffusion Models}

\section{Hypotheses}

In a system of reacting and diffusing chemicals, it is possible for a spatially heterogeneous chemical concentration to evolve from an essentially homogeneous initial distribution (Turing, 1952). If cells responded to this chemical concentration by differentiating wherever the concentration was above a threshold value, then the spatial pattern of chemical concentration would be reflected by a spatial pattern of cell differentiation.

\section{Mathematical Formulation}

A two-chemical reaction-diffusion (RD) system has the form

$$
\begin{aligned}
& \frac{\partial u_{1}}{\partial t}=D_{1} \nabla^{2} u_{1}+f\left(u_{1}, u_{2}\right) \\
& \frac{\partial u_{2}}{\partial t}=D_{2} \nabla^{2} u_{2}+g\left(u_{1}, u_{2}\right)
\end{aligned}
$$

in a domain $\Omega$ with initial conditions $u_{\mathrm{i}}(\mathbf{x}, 0)=u_{i}^{0}(\mathbf{x}, 0), i=1,2$, where $u_{1}(\mathbf{x}, t), u_{2}(\mathbf{x}, t)$ are the chemical concentrations at position $\mathbf{x}$ and time $t, D_{1}$ and $D_{2}$ are diffusion coefficients, and $f$ and $g$ describe the reaction kinetics. Such models have been extensively studied for different $f$ and $g$ (see, e.g., 
It is often asserted that this model can account for the duplication of skeletal elements observed after transplantation of a donor ZPA to the anterior of a host wing bud (see, e.g., Wolpert, 1981). However, the interpretation of the model necessary to account for duplication requires tissue that was initially a sink to lose this property and to be able to support nonzero morphogen concentration. With multiple ZPA grafts an argument similar to the above predicts fused or abnormally thick digits, contrary to observation. This suggests that the gradient model needs to be supplemented by another mechanism which keeps the digits discrete (Wolpert and Hornbruch, 1981). Furthermore, the model cannot account for the results of certain other experiments. For example, limbs from which the ZPA has been excised can develop with AP polarity. In this case, limbs may be responding to the progeny of ZPA cells or may be exhibiting a memory mechanism. As mentioned in Section III, several nonlimb grafts can also give rise to duplications in the limb. Perhaps these tissues are also producing retinoids, suggesting a more general role for retinoids in development.

The above model predicts that transplants of ZPA at positions along the AP axis of a stage 16 wing bud should result in either the elimination of the humerus, or its duplication, or the formation of a mirror-image duplicate of a single humerus, depending on the position of the graft and on the threshold concentration. However, in no case is the humerus eliminated and rarely is it duplicated. Either a normal, or a mirror-image duplicate humerus forms in most cases (Wolpert and Hornbruch, 1987).

The gradient model assumes that diffusion occurs in one dimension, but, of course, diffusion from a source in the limb will be three-dimensional. Thus one has to address the issue of appropriate boundary conditions at the distal tip, the proximal limit, and the dorsal and ventral boundaries of the limb. Furthermore, a model based on the establishment of a concentration gradient via diffusion and a source-sink mechanism, and its interpretation through a threshold mechanism, is necessarily a sensitive process (Summerbell, 1979), yet limb development is a robust process.

\section{B. Progress Zone Model}

The progress zone model was proposed to account for skeletal differentiation along the PD axis (see, e.g., Wolpert et al., 1975).

\section{Hypotheses}

This model is based on the hypothesis that as cells emerge from the progress zone they differentiate according to the number of cell divisions experienced in the progress zone. That is, a cell's positional information is determined by the time spent in the progress zone. 


\section{A. Gradient Model}

The gradient model was proposed to account for skeletal pattern along the AP axis of the developing limb.

\section{Hypotheses}

Wolpert $(1969,1981)$ proposed that the ZPA was a source of some unknown chemical (a morphogen) which set up a gradient in the AP direction by diffusion and degradation. The morphogen distribution set up by such a mechanism was hypothesized to determine positional information for each cell at each point along the AP axis. This, in turn, would be converted into a positional value for each cell by an unspecified cellular mechanism depending on the cell's genetic constitution and developmental history. Such a spatial pattern of positional value could then be transformed into a spatial pattern of differentiation if a cell differentiated when its positional value lay between certain threshold values.

\section{Mathematical Formulation}

Mathematically, this model has the form

$$
\frac{\partial S}{\partial t}=D \frac{\partial^{2} S}{\partial x^{2}}-\alpha S, \quad x \in[0, d]
$$

with initial conditions $S(x, 0)=0$ and boundary conditions $S(0, t)=S_{0}$, $S(d, t)=0$, where $S(x, t)$ is the concentration of morphogen at position $x$ and time $t, D$ is the diffusion coefficient of the morphogen, and $\alpha$ the rate of linear degradation of morphogen. The boundary conditions incorporate the assumptions that the ZPA (at $x=0$ ) is a source of morphogen and that the anterior margin of the limb $(x=d)$ is a sink. The condition at $t=0$ simply says that, initially, there is no morphogen.

The steady state for this system satisfies the equation

$$
D \frac{d^{2} S}{d x^{2}}=\alpha S
$$

with the aforementioned boundary conditions, and has the solution

$$
S(x)=\frac{S_{0} \sinh [\gamma(d-x)]}{\sinh (\gamma d)}
$$

where $\gamma^{2}=\alpha / D$.

The gradient model assumes that cells at position $x$ along the AP axis of the limb are exposed to a morphogen concentration $S(x)$ given by Eq. (3). The skeletal elements are assumed to be specified by certain limiting morphogen concentrations. If a cell is exposed to a concentration that lies between these limits then it differentiates into the appropriate element. 
cell cultures expressed the myogenic phenotype in high oxygen concentrations, and the chondrogenic phenotype in low oxygen concentrations. They proposed that the vascular system may be responsible for setting up different environments appropriate for different types of differentiation. Except for a peripheral avascular zone subjacent to the ectoderm, the vascular system is uniformly distributed in the limb bud up to stage 20 . By stage 22 there are fewer blood vessels in the core region than in the more peripheral regions of the limb and by stage 24 the core is essentially avascular while the prospective muscle-forming tissue is still well vascularized. The extreme periphery of the limb maintains an avascular zone due, perhaps, to the inhibitory effect of hyaluronic acid present in this region (Feinberg and Beebe, 1983). Caplan (1985) hypothesizes that this vascular pattern, which he claims serves as a prepattern for myogenesis, may be set up by the pattern of mitotic activity in the limb mesenchymal cells. It appears that avascularity forms in the core of the limb simultaneously with the formation of precartilage aggregates, as indicated by increased sulphate-35 uptake, at stage 22 (Fraser, 1986) but prior to overt differentiation of cartilage in the more distal skeletal elements (Latker et al., 1986; Feinberg et al., 1986; Hallman et al., 1987).

However, the role of the vasculature in differentiation is a controversial issue. Searls (1968) showed that chondrogenesis of the digits can occur in an avascular system. Recent observations (Schramm and Solursh, 1990) suggest that precartilage and premuscle cells sort out in avascular culture and differentiate into cartilage and muscle, respectively.

\section{E. Role of Extracellular Matrix}

Cells may differentiate if exposed to the appropriate chemical cues from the ECM (Solursh et al., 1990). Fibronectin and laminin are among the possible candidates to provide such cues. For example, with the onset of chondrogenesis, an increase in the concentration of fibronectin is observed to occur in regions corresponding to where chondrogenic differentiation is going to occur (Dessau et al., 1980).

Chiquet et al. (1981) proposed that limb bud mesenchymal cells form a meshwork of fibronectin which guides myoblast migration. However, fibronectin appears to be ubiquitous in the wing bud so it is not clear how it could act as a guide for myoblast cells (Venkatasubramanian and Solursh, 1984). A more plausible role for fibronectin during these early stages is as a substrate mediating myoblast response to a chemotactic gradient occurring in the vascular network (Kosher et al., 1982).

Prior to the onset of overt myogenesis, the position of future dorsal and ventral myogenic areas is marked by localization of laminin (Solursh and 
collagen gel. Their results show that prestage 16 wing mesenchyme is dependent on the presence of ectoderm for its growth and subsequent chondrogenesis. In contrast to this stimulatory effect of ectoderm on differentiation in early mesenchyme, ectoderm from both stages inhibits chondrogenesis in the stage $23 / 24$ mesenchyme. The stimulatory effect requires cell contact, whereas the inhibitory effect can be transmitted across filters. When cartilage did form, it was always at a distance from the ectoderm.

Zanetti and Solursh (1989) found that antibodies to integrin receptors alleviate the antichondrogenic effect of ectoderm-conditioned medium and cause limb bud mesenchymal cells to become rounded and to detach from collagen gels. It can be shown, however, that ectoderm-conditioned me dium which inhibits chondrogenesis contains insufficient amounts of fibronectin to account for its inhibitory effect. Limb bud mesenchymal cells cultured on collagen in either control or ectoderm-conditioned medium synthesize fibronectin. Thus, the antichondrogenic effect of ectodermconditioned medium may require interaction of ectodermal factors with mesenchymal cell fibronectin or other associated extracellular matrix components.

The above discussion on the role of the ectoderm has been based on experiments carried out in culture. As pointed out before, the intact limb may behave in a different manner. To this end, Martin and Lewis (1986) observed that removal of the dorsal ectoderm still permits normal limb development. They removed dorsal wing bud ectoderm in the chick embryo by irradiation with UV light at stages 17-19, keeping the AER intact. They found that over half the limbs treated in this way developed approximately normal skeletons. Thus, the effects of ectoderm in vivo seem to be different from those in vitro. In their experiments, however, it took an unknown time for the ectoderm to regress after UV treatment. Therefore it is not clear at exactly what stage the ectoderm was removed. Martin and Lewis try to resolve this apparent contradiction by suggesting that a core versus periphery determination of cell character may occur before other aspects of the skeletal pattern are determined. This might be disrupted by the drastic processes involved in setting up a micromass culture.

Hurle and Gañan $(1986,1987)$ removed the AER from interdigital spaces of the chick leg bud at stages 28-30. They found that the underlying mesenchymal cells rounded up, condensed, and, in some cases, formed an extra digit. This may be interpreted as supporting the hypothesis that the ectoderm inhibits in vivo chondrogenesis by inhibiting cells from rounding up.

The DV ectoderm has a marked effect on DV polarity in the developing wing bud as discussed in Section III, B. The basis for the differences in dorsal and ventral ectoderm on skeletal morphogenesis is unknown. 
Kimata, 1990). Fibronectin appears somewhat more concentrated at these sites (Dessau et al., 1980) and fibronectin message is maximal at the time of precartilage aggregate formation (Kulyk et al., 1989b). Proteoglycan M, as well as other extracellular matrix components that bind the lectin peanut agglutin, are localized in precartilage aggregates (Shinomura et al., 1990). Thus, there are a number of known changes in the extracellular matrix that are associated with precartilage aggregate formation.

Ede and Flint (1972) found that aggregates formed in vitro consist initially of a population of mesenchymal cells. Initiation of chondrogenesis occurs at the center of the condensation and expands centrifugally. It has been suggested that condensing foci may be centers of production of some chemotactic substance leading to aggregation (Ede, 1971; Ede and Agerbak, 1968). Ede et al. (1977) found that in culture, cells on the periphery of the chondrogenic focus are directed centripetally inwards, but cells in nonchondrogenic areas move randomly. This suggests a wave of morphogenetic activity spreading outwards from a focal point, perhaps involving ECM assembly (Frenz et al., 1989; Frenz and Newman, 1989).

It is known that cartilage formation occurs in cultures of high-density mesenchymal cells but not in cultures with intermediate densities (Osdoby and Caplan, 1979, 1980; Solursh and Reiter, 1980; Cottrill et al., 1987b). Conditions that permit the association of groups of mesenchymal cells in a three-dimensional mass rather than as a monolayer favors chondrogenesis, but a critical number of limb mesenchymal cells must be in contact. Similar interactions might be important in vivo. Hurle et al. (1989) found that removal of interdigital AER together with some underlying mesoderm gave rise to condensations which, in some cases, formed an extra digit. However, if enough mesoderm was removed, the condensation disaggregated and extra cartilage was not observed. They suggest that this may be due to the smaller size of aggregate.

\section{Cell Shape}

One condition that may determine the expression of the chondrogenic phenotype is cell shape or cytoskeletal organization (Zanetti and Solursh, 1989). Cell shape changes could potentially mediate the effects of cell-cell association. A single mesenchymal cell can differentiate into cartilage if it is kept in a rounded shape. This can be achieved by culturing the cell on a substratum on which it does not attach and flatten (Solursh et al., 1982) or by treatment with cytochalasin $\mathrm{D}$, which disrupts the actin cytoskeleton of the cell, causing it to adopt a rounded configuration (Zanetti and Solursh, 1984). Conversely, certain environments that cause the cell to adopt a flattened morphology inhibit chondrogenesis; for example, culturing in ectoderm-conditioned gels (Zanetti and Solursh, 1986) or treatment with 
ing population. Similarly, by using muscleless limbs for high density cultures made by prior removal of somites, Cottrill et al. (1987a) found enhanced chondrogenesis compared to cultures containing muscle cells. These results suggest a role for myogenic cells in the differentiation of still uncharacterized classes of nonchondrogenic cells. This possibility warrants further investigation.

Although nearly all the literature on differentiation in the wing bud has concentrated on chondroblasts and myoblasts, Lewis (1977) found that out of the initial cell population of a stage 23 wing bud, only $12 \%$ differentiate into muscle and cartilage. The other $88 \%$ is concentrated mainly in the elbow and perichondrial regions. This cautionary paper suggests that perhaps more attention should be paid to other cell types. Studies on other connective tissue cell types have been hampered by the lack of specific molecular markers. There is evidence that the development of limb muscle pattern is controlled by connective tissue cells (Chevailler and Kieny, 1982). Tissue from the peripheral region of a stage 23-24 limb which would normally form muscle can form cartilage in explant and cell cultures (Ahrens et al., 1979), suggesting the existence of cells capable of a wide variety of developmental potential. However, we shall concentrate mainly on the two aforementioned cell types as they have been the ones studied extensively.

\section{A. Chondrogenesis}

A mesenchymal cell differentiates into cartilage as it secretes components of cartilage matrix in a sequential fashion (Stirpe and Goetnick, 1989). Differentiation occurs at the center of the forming skeletal element and spreads out (Franzen et al., 1987; Schmid and Lisenmayer, 1985). Once differentiation begins, there is a period of time in which the cell phenotype can be influenced by the environment. Therefore, as well as analyzing when differentiation occurs, it is important to find out when a cell phenotype has become relatively stable in situ.

\section{Stabilization of Differentiation}

Searls (1967) implanted blocks of tissue from donors into same-stage host embryos. He found that every block stayed intact and differentiated according to its local environment; for example, if a block that would have formed cartilage in the donor is implanted in a position where the host cells would normally form some cartilage and some soft tissue, the donor block followed this fate. He concluded that migration does not occur in prechondrogenic cells and that prior to stage 22 every mesenchymal cell is equally capable of chondrogenic differentiation. At that stage, cells in the 
ment than the controls. Development was incomplete because the normal AER regressed. Thus it appears that mesoderm responds to the stimulus of the AER by growing distally and provides a factor which is necessary for continued maintenance of the AER.

\section{Proximal-Distal Differences}

There appear to be differences in some surface properties of proximal and distal cells. For example, proximal cells aggregate faster than distal cells. The distal portion of the limb stains more intensely for syndecan than does the proximal (Solursh et al., 1990). There also appears to be a PD gradient in chondrogenic capacity (Solursh, 1984a). At stage 23 or 24, distal cells have an extensive chondrogenic capacity and form a solid mass of cartilage, whereas proximal cells fail to differentiate under some culture conditions, but will express chondrogenesis if treated with cyclic AMP or if mixed with one distal cell for every ten proximal cells (Swalla et al., 1983). Solursh (1984a) proposed that a maturation-related increase in binding sites for prevalent extracellular matrix (ECM) components such as fibronectin could have a central role in regulating the onset of chondrogenesis during normal development (see also Swalla and Solursh, 1984).

Cell response to RA varies along the PD axis. Ide and Aono (1988) found that the promotion of proliferation and chondrogenesis of mesodermal cells by RA is stage-, dose-, and position-dependent. Growth promotion in distal cells occurred at stage 20-23; no promotion was observed at stage 25 , and at stage 27 proliferation was inhibited. Increasing RA concentration induced growth promotion significantly in distal cells at low concentration but promotion was reduced at high levels of RA. No growth stimulation was observed in proximal cell cultures independent of RA concentration. Retinoic acid inhibited chondrogenesis in proximal cell cultures. Distal cell chondrogenesis was promoted with low doses of RA but inhibition began to occur at high doses. Paulsen and Lang (1990) have been able to separate the proliferative and chondrogenic modulating actions of RA further by comparing responses of a subdistal region to distal and proximal regions. The results emphasize the distinct nature of these two actions of RA and the importance of differences in the mesenchymal cells themselves in the actions of the retinoids.

\section{Gene Regulation of Pattern Formation}

With molecular biological approaches rapid progress is being made in the identification of genes that regulate pattern formation. Drosophila has led the way in this area and many homologous genes have now been 
found that a stage 24 host limb mesoblast plus a grafted stage 19/20 donor progress zone led to a composite limb consisting of stylopod-zeugopodstylopod-zeugopod-autopod. Conversely, the tip of a stage 24 wing bud grafted onto a stage 19 stump led only to the formation of the autopod. This suggests that the limb bud does not possess regulative ability along the PD axis and contradicts Kieny's results. Discrepancies in the accuracy of the fate maps used in these experiments may have led to differing interpretations of the results. Alternatively, regulation may not have occurred because one of the cell populations (stage 24) may have already differentiated.

\section{Apical Ectodermal Ridge}

The ectoderm at the distal tip of the limb bud forms the AER, which is induced by the mesoderm between stages 14 and 16, and appears at late stage 18 (Todt and Fallon, 1984). At first the ridge is almost symmetrical with respect to the PD axis. Subsequently, the thickening is most prominent posterior to the PD axis (Saunders, 1977). Removal of the AER up to stage 28 causes outgrowth to cease (Saunders, 1948; Summerbell, 1974b), and a truncated limb develops with skeletal deficiencies in its distal portion. Rubin and Saunders (1972) showed that the AER has the ability to induce complete wings from early mesoblasts, but loses this property during stage 29. It appears that PD pattern is a function of the age of the mesoblast, not the AER. For example, stages 23-25 ectoderm on stages 18-20 mesoblasts grew into normal limbs, while stage 19 ectoderms on the tips of stage $22-25$ mesoblasts gave rise only to the distal portion of the limb. The AER appears to be maintained by the underlying layer of tissue, the mesoderm, which also controls limb type (Zwilling, 1961). The AER is not only essential for outgrowth and distal development of the limb bud, but it also appears to maintain the shape of the limb bud and its orientation determines the shape and size of the bud (Hornbruch and Wolpert, 1970; Lee and Tickle, 1985).

In micromass cultures, the AER has the ability to delay the differentiation of associated mesenchyme and stimulate the formation of a mesenchymal outgrowth (Reiter and Solursh, 1982). These results suggest that in vivo the AER maintains the distal mesenchyme adjacent to it-in the region known as the progress zone-in an undifferentiated state and stimulates limb outgrowth by maintaining a high mitotic index in the subridge mesenchyme (Hornbruch and Wolpert, 1970; Summerbell and Lewis, 1975). The AER is no longer visible by about stage 33 and may regress according to an inherent timing mechanism (Rubin and Saunders, 1972).

Saunders (1948) found that the level of truncation as a result of removing 
rides (Searls, 1965) at proximal levels in the stage 22 limb where areas of high precartilage cell density in the central proximal regions are observed (Fell and Canti, 1934). By stage 23, there is an increase in cell contact in dorsoventral proximal regions of presumptive myogenesis (Gould et al., 1972). Summerbell (1976) observed inhomogeneity in Alcian Green staining of the wing bud to first occur at stage 24 , when the humerus and ulna become visible. The radius is clearly seen by stage 25 , posterior wrist parts are visible by stage 26 , and the anterior wrist parts by stage 28 . Digit $V$, the first metacarpal to become visible, stains by stage 26 but disappears by stage 30 . The skeletal pattern is complete by stage 34 , when the tip of digit II appears. Osteogenesis begins at stage 36.

\section{Origin of Skeletal Elements}

Saunders (1948) used carbon marks to study the elongation of the limb and concluded that the origin of successively more distal parts of the wing is in the apical portion of the bud. Stark and Searls (1973) constructed a fate map by transplanting blocks of tritiated thymidine labeled cells into the developing limb bud (stages 18-24) and following their fate through to later stages. The blocks remained intact and did not shift their position during wing outgrowth; blocks implanted at the base of the bud were found in the girdle region, those implanted in the center of the wing were found in the humerus and ulna-radius regions, and those implanted directly beneath the AER were found in the digits. Their fate map shows that regions of prospective skeletal development can be mapped back to areas in the bud as early as stage 18 . The claim that the prospective digit region is present at such early stages is supported by Zwilling (1956a), who showed that blocks of limb mesenchyme implanted directly beneath the AER as early as stage 19 participated in digit formation, and by Searls (1968), who showed that thin strips of stage 19 limb apical mesoderm with the AER attached gave rise to digits if grown in avascular culture.

\section{Stabilization of Pattern}

Several studies have been carried out on the regulative capacity of the wing bud along the PD axis. Stark and Searls (1974) did so by excising prospective long bone regions from stages 19 to 24 to see whether they would regenerate, and by rotating the " $Y$ " of the prospective elbow along the PD axis. They concluded that prospective long bone regions of the wing are completely regulative prior to stage 22 but become stabilized between stages 22 and 24 . By stage 24, removal of even a single prospective skeletal area resulted in the deletion of that element in almost all cases. Prior to this stage the missing skeletal element did not necessarily reflect the prospective element area excised. The radius-ulna region seemed to 
respond by differentiating if its concentration lies within certain threshold values (Tickle, 1983). In a quantitative study on the effects of implanting beads which release RA at the anterior wing bud region, it was found that digit pattern was dose-dependent (Tickle et al., 1985); low concentrations led to a normal digit pattern, higher concentrations produced supernumerary digits, but still higher concentrations led to wings in which only the humerus and a knob of cartilage were formed. In a similar type of experiment, Eichele et al. (1985) found duplication to be stage-dependent; implantation of the bead at stage 20 led to complete duplication, but implantation at stage 22 led to incomplete duplication.

These experiments show that the in vivo effects of RA are concentration- and dose-dependent. Similar behavior is observed in vitro. Paulsen et al. (1988) found that RA has a biphasic dose-related effect on chondrogenesis and myogenesis in culture. At low concentrations it stimulates chondrogenesis but has no effect on myogenesis. At high concentrations it inhibits both these processes.

Thaller and Eichele (1987) showed that RA [and recently another RA metabolite (Thaller and Eichele, 1990)] does indeed occur in the intact developing limb and is more concentrated posteriorly. The recovered RA induced duplication patterns similar to those produced by synthetic RA.

It has been observed that a cytoplasmic RA-binding protein (CRABP) occurs largely at the distal tip of the growing limb bud (Maden et al., 1988). It appears that the CRABP occurs in an AP gradient with its high point at the anterior end, opposite to that of the RA gradient. This would result in an almost flat distribution of RA/CRABP complex across the limb bud which would steepen the gradient of free RA which, in turn, may be involved in providing the AP polarity in the limb.

The effects of retinoids on gene activity appear to be mediated through nuclear retinoid binding proteins (RAR), of which an increasing number have already been identified. These include $\operatorname{RAR} \alpha, \beta$, several alternatively spliced variants of the $\gamma$ receptor (Kastner et al., 1990), and RXR (Mangelsdorf et al., 1990). To date all of these have similar DNA binding domains. In the mouse limb bud mRNA for both RAR $\alpha$ and $\delta$ but not RAR $\beta$ are present uniformly throughout the mesenchymal stage limb bud (Dollé et al., 1989b). Subsequently, RAR $\delta$ transcripts become localized to cartilage-forming regions (Ruberte et al., 1990) and those for RAR $\beta$ are present in the interdigital mesenchyme. The specific roles for these nuclear receptors in pattern formation remain to be elucidated. It will be most important to characterize the factors that regulate their spatial expression and the genes whose activity is in turn regulated by retinoid-receptor complexes. 


\section{Development along Limb Axes}

Pattern development in the limb is a highly intricate process involving cell-cell, cell-tissue, and tissue-tissue interactions which change with time and position in a complicated three-dimensional geometry which is also changing with time. In order to simplify the system, research has concentrated mainly on investigating pattern formation along each of the three limb axes. This has consisted of observing the sequential process of skeletal and musculature development, identifying specialized regions in the limb which appear to control polarity, and examining the regulative properties of the skeletal pattern. We consider development along each axis in turn.

\section{A. Anterior-Posterior Development}

The fate maps of Stark and Searls (1973) show that the anterior half of the limb bud gives rise to part of the humerus, the radius, and digit II; the posterior half gives rise to part of the humerus, the ulna, and digits III and IV. There is also progressive displacement of apical mesoderm in the preaxial direction (Bowen et al., 1989). The control of AP polarity appears to lie in a specialized group of cells at the posterior margin of the limb bud known as the zone of polarizing activity (ZPA) (Tickle, 1981b).

\section{Zone of Polarizing Activity}

Saunders and Gasseling (1968) found that if they transplanted a region of cells from the posterior peripheral mesenchymal region of the developing chick limb to the anterior of the limb, the resulting limb had a duplicated digit pattern. They named this region the zone of polarizing activity (ZPA) and proposed that it was the source of some chemical, termed morphogen, which set up an AP gradient to which cells responded in some way. The patterns of muscles, tendons, blood vessels, and nerves are also duplicated under ZPA grafting (Shellswell and Wolpert, 1977). Duplication in tip reversal experiments appears to occur only if part of the ZPA is included in the reversed tip (Saunders et al., 1958; Saunders and Gasseling, 1963; Fallon and Crosby, 1975).

MacCabe et al. (1973) first assayed polarizing activity at stage 15/16 and found that it remained until stage 28 . Removal of the ZPA at stages 17-18 led to all limbs sowing posterior defects. However, removal at stages 19-24 led to normal development, including normal AP pattern, in half of the limbs examined. This result questions the role of the ZPA's influence on AP polarity at later stages of development, although it does not rule out its importance during the initial stages of polarity establishment. Further- 
Section IV we consider the process of cell differentiation. In Section V we review several theoretical models that have been proposed to account for limb development. We discuss their successes and failures. In Section VI we consider what major questions remain unanswered, and we discuss the potential use of mathematical modeling in limb development.

\section{Brief Overview of Limb Development}

\section{A. Sequence of Events}

Hamburger and Hamilton (1951) studied chick development through the entire period of incubation with the aim of identifying and designating embryos on the basis of external characters independent of chronological age and size. They chose intervals of three somites as "stages". Embryos with intermediate numbers of somites were designated by + or - . The first somite begins to disperse after stage 10 and was not counted thereafter. The presomite stages were numbered 1-6 (first day of incubation). These stages have now become the standard frame of reference in chick limb development. The wing site is determined by stage 8 (26-29 hours of incubation) and limb outgrowth is visible by stage 17 . The first skeletal element is visible by stage 24 and the last element is seen by stage $34(\sim 8$ days of incubation). Up to stage 23 the average duration of a stage is $\sim 4$ hours; thereafter, it increases to about 6 hours.

\section{B. Initiation of Limb Site}

It is not known how the site of the future limb is determined in the developing embryo, although it is known to happen very early. Rudnick (1945) and Chaube (1959) found that transplanted prospective limb tissue from stage 8 donors had the capacity to differentiate normally in the absence of the material that normally surrounds it. It was already known that in the newt a region of the lateral plate mesoderm somatopleure at the tailbud stage was capable of forming a forelimb when transplanted to a different region of the embryo (Harrison, 1918). The limb forming capacity is a property of the lateral plate mesoderm. Furthermore, the capacity to form a fore- or hindlimb bud is already a stable property of the mesoderm even before the appearance of the limb bud (Zwilling, 1955; Saunders et al., 1955, 1959). This property may be associated with the establishment of the anterior-posterior (AP) axis of the embryo (Krabbenhoft and Fallon, 1989). 